\title{
Hereditary metabolic myopathy with paroxysmal myoglobinuria due to abnormal glycolysis ${ }^{1}$
}

\author{
L.-E. LARSSON, H. LINDERHOLM, R. MÜLLER, T. RINGQVIST, \\ AND R. SÖRNÄS \\ From the Departments of Clinical Physiology and Clinical Neurophysiology and Neurology, \\ University of Umeå, Sweden
}

Extensive trauma of striated muscles, such as in the crush syndrome (Bywaters, 1944), and in severe electrical injuries, especially when caused by a hightension current (Fischer and Rossier, 1947), sometimes produces myoglobinuria. Myoglobinuria also occurs in diseases with degeneration of large muscle masses, such as occlusive diseases of the peripheral arteries (Bywaters and Stead, 1945), acute forms of polymyositis (Günther, 1924; Paul, 1924), and the epidemic Haff disease (Berlin, 1948). Myoglobinuria of unknown aetiology has also been described in some 50 cases under such synonyms as idiopathic paroxysmal myoglobulinuria, paroxysmal paralytic myoglobinuria, acute recurrent rhabdomyolysis, and paroxysmal recurrent rhabdomyolysis.

Until recently our knowledge of the pathophysiology of idiopathic paroxysmal myoglobinuria was extremely meagre. Korein, Coddon, and Mowrey (1959) discussed the possibility of oxygen deficit in the affected muscles during activity. Schmid and Mahler (1959), however, demonstrated in a patient with paroxysmal myoglobinuria 'a defect in the phosphorylase system of the muscle, which precludes breakdown of glycogen and eliminates anaerobic glycogenolysis as a source of energy for muscular contraction', a disturbance of the muscle metabolism of the type described by McArdle (1951).

We have studied five families, of which 14 members had a myopathy with poor physical performance since childhood. Nine had on some occasion passed dark urine, and in three of them spectrophotometry had demonstrated myoglobin in the urine. Eight members of the five families were examined more extensively. Their physical performance proved poor, the rate of blood flow during exercise was abnormally high in relation to oxygen uptake, and the concentrations of the lactate and pyruvate in the blood were high for the work performed and thereby suggested abnormal glycolysis. Muscular exercise produced electromyographic abnormalities. The metabolic

'Preliminary reports were presented at the Meeting of the Scandinavian E.E.G. Society in Stockholm on 13 May 1961. disturbance is probably inherited and is most likely transmitted by a monohybrid recessive autosomal gene.

\section{MATERIAL}

The 14 patients belonged to five families (A-E). Of these patients, four (A1-4) belonged to family A; two (B1-2), to family B; three (C1-3), to family C; four (D1-4), to family D; and one (E1), to family E.

Eleven patients (A1-4; B1, 2; C1, 3; D2, 3 and E1) were admitted to the Department of Neurology, University hospital of Umeå. The remaining three $(C 2, D 1$, and D4) were examined at the Out-patient Department. The 11 in-patients were examined neurologically. Laboratory studies included determination of $\mathrm{Hb}$ concentration, the number of blood cells, erythrocyte sedimentation rate, non-protein nitrogen, serum creatinine, serum haptoglobulins and glucose tolerance, as well as measurement of the blood sodium, potassium, chlorides, bicarbonate, and transaminases before and after physical exercise. The urine was studied for protein, for porphyrins and myoglobin, and its sediment was examined microscopically. The urinary creatinine and creatine were also measured. In all 14 cases clinical examination included determination of the basal metabolic rate, electrocardiography with the patient resting in the supine and standing postures, as well as during and after exercise, phonocardiography and oscillometry, except in one case (A1), in which only some of the examinations were performed. Only abnormal results of the examinations will be described, and then either in the Case Reports or under Results.

The physical performance of the 11 in-patients and one (D1) of the patients examined at the Out-patient Department was assessed. In seven (A2-4, B1, C1, D2, and E1) of them determinations were made of the total haemoglobin, blood volume, and heart volume, as well as of lung function. Further, the concentration of the blood lactate during rest and exercise and the haemodynamics in each case was examined by catheterization of the heart and of peripheral vessels (see under Methods). In three cases (B2, C3, and D1) only some of these examinations were performed. Electromyographic examination at rest was done in nine cases (A1-4, B1, C1, D2-3, E1) and both before and after physical exercise in eight (A2-4, B1, 
D2-3, E1). Two patients (C2 and D4) were examined only neurologically.

Apparently healthy male and female volunteers, aged 20-30 years, served as controls.

\section{METHODS}

PHYSICAL PERFORMANCE AND RELATED BODY PARAMETERS Physical performance was assessed from the results of a work test according to Sjöstrand (1947) and Wahlund (1948). Exercise consisted of cycling on an ergometer (Holmgren and Mattsson, 1954) with resistance increased stepwise at six-minute intervals. Both leg and arm exercises were performed in the sitting posture. The physical working capacity $\left(\mathrm{PWC}_{\mathbf{1 7 0}}\right)$ was defined as the estimated work load resulting in a pulse frequency of 170 beats per minute during cycling with the legs in the sitting posture. The total haemoglobin, blood volume, and heart volume were determined in principle in accordance with the methods described by Holmgren, Jonsson, Levander, Linderholm, Sjöstrand, and Ström (1957).

HAEMODYNAMICS AND RESPIRATION Right heart catheterization combined with the percutaneous introduction of polyethylene catheters into peripheral veins such as the femoral vein, the axillary vein and superficial veins of the lower arm according to Seldinger (1953), was used in the haemodynamic investigation of the patients and for determination of the oxygen content, the concentration of lactic and pyruvic acid in different parts of the vascular system at rest and during exercise. With the patients cycling in the supine position the cardiac output was determined by Fick's direct method. Arm exercises in the sitting posture were usually performed one to two hours after the leg exercises or, occasionally, on the following day. During these exercises blood samples were collected only from the indwelling catheters in the peripheral vessels.

In the electrocardiographic examinations chest and limb leads were used. Lung function studies included determination of the lung volumes, ventilatory capacity, and distribution of the alveolar gas.

The oxygen saturation of the blood was determined photometrically (Holmgren and Pernow, 1959) or by the method of Van Slyke and Neill (1924). The concentration of the blood lactate was measured by Ström's (1949) modification of a method described by Barker and Summerson (1941). The pyruvic acid was measured by a method devised by Friedemann and Haugen (1943), as modified by Huckabee (1956). The carbon dioxide tension and standard bicarbonate of the arterial blood were determined essentially by the method of Jørgensen and Astrup (1957).

ELECTROMYOGRAPHY The muscle action potentials were recorded with concentric needle electrodes with an outer diameter of $0.65 \mathrm{~mm}$. The area of the inner platinum lead was 0.07 sq. $\mathrm{mm}$. Condenser coupled amplifiers were used. The frequency range of the recording system including the needle was measured as $2-8,000 \mathrm{c} / \mathrm{s}$ within $3 \mathrm{~dB}$.
After the patient had rested for one day a large number of muscles were examined according to a routine metho comprising evaluation of the duration, amplitude, shape and frequency of the action potentials directly from the cathode-ray screen.

In addition, before and after exercise on the cycle ergometer photographs were taken of action potentials picked up from 30 to 40 points distributed evenly in the entire volume of the muscle studied. The total duration. of the action potentials was measured. The percentage frequency of the action potentials with four phases (tetra-. phasic) and of those with more than four phases (poly $\vec{F}$ phasic) was determined. The number of phases was judgeff according to Buchthal, Guld, and Rosenfalck (1954a)을 The amplification of the photographed action potentials was $50 \mu \mathrm{V} / \mathrm{mm}$. deflection.

\section{CASE REPORTS}

CASE A1(L.M.) A seamstress, born in 1933, had always $\overrightarrow{8}$ had unusually well-developed calves. Ever since early childhood she had palpitation and dyspnoea even of moderate physical exertion. She therefore could not rut: so fast or so long as other children. At 10 years the muscles of the extremities became tender, and muscular activity caused cramp-like pain. She could only walk for short distances without stopping and resting. Neitber could she do any work engaging her arms for more the. a short period at a time. The severity of the symptôp $\vec{s}$ varied. Thus, during periods of poor physical performagice even chewing caused dyspnoea and palpitation.

In the autumn of 1951 she had a fairly sudden exacer $\overline{3}$ ? tion, and for a couple of months she could not walk mor than a few steps without severe leg pain. The legs wore then very weak and she spent the greater part of her the in bed. On 30 October 1951 she was admitted to Department of Internal Diseases, Umeå Hospital, wheræ̧ she remained until 8 December 1951. She then had severe resting dyspnoea and tachycardia (140 beats/min.). The blood pressure was $150 / 90 \mathrm{~mm}$. Hg. She could then barelys lift her legs from the bed. The strength of the shoulders and elbow was considerably reduced, while that of thg hands was almost normal. She could not rise from th ground without the help of her arms and hands. The biceps reflexes were normal, but no other muscle reflexe could be elicited. Babinski's sign was negative on both sides. The abdominal reflexes were normal. Sensibilitge was normal. Body temperature on admission was $38^{\circ} \mathrm{C}$ but afterwards normal. The E.S.R. was $20-9 \mathrm{~mm}$. in one hour. There was no proteinuria and the urinary sedimen was normal.

During the following years her general condition was fairly good.

In 1954 she had another exacerbation and was bed $\oint$ ridden for a few months. Afterwards, however, she coulæ manage her housework but for a short period each year? when she experienced a transient relapse. Her working capacity was, however, substantially reduced the whol time by dyspnoea, tachycardia, and muscle pain.

During the last nine years before admission to thes Department of Neurology the muscles of the hip and abdomen had been weak. She had a waddling gait, she् 
could not sit up in bed without using her hands and even found it difficult to stand up from a low chair.

In October 1960 the patient became worse after a fairly long period of physical exertion, and at the end of November of that year she had continuous pain in the legs, arms, and back as well as cramp-like pain in the calves. Her legs became weak and the dyspnoea and tachycardia increased, she became nauseated and vomited, and was finally bedridden. It was then that darkness of the urine was noted for the first time. She was admitted to the Department of Neurology on 29 November 1960.

Physical status The patient was of ordinary body build. She had severe resting dyspnoea and tachycardia (120 beats/min.). The lower legs were slightly oedematous. Physical examination of the heart revealed no pathological signs. Blood pressure was $155 / 100 \mathrm{~mm}$. Hg. The body temperature was slightly above normal.

Neurological status There was marked hypertrophy of the calves which were hard and tender to palpation. No muscular atrophy was observed. Severe pareses of the extremities, most advanced in the proximal musculature, was noted. The patient could not stand unaided, she could raise her legs only with difficulty, she found it difficult to rise from the ground without the help of her arms and hands, and she could barely raise her arms above the horizontal plane. The muscle reflexes could be elicited in the arms, but not in the legs. The abdominal reflexes appeared normal. Babinski's sign was negative on both sides. Sensibility was normal.

Urine analysis The urine contained protein, but the sediment was microscopically normal. Myoglobin was identified spectrophotometrically and determined quantitatively as pyridine haemochromogen $(0.9 \mathrm{mg} . / \mathrm{ml}$. on 30 November and $1.2 \mathrm{mg} . / \mathrm{ml}$. on 1 December). No porphyrins were demonstrable. The blood bicarbonate level was $4 \mathrm{mM}$./litre.

Electrocardiography showed sinus tachycardia.

One day after admission the patient became worse, and after a period of increased hyperventilation respiratory distress occurred, and she was placed in a respirator. During artificial respiration her condition improved, but she suddenly died two days later from circulatory collapse.

Necropsy Professor Fajers performed the necropsy. Early 'crush nephritis' with pigment casts was found but otherwise no signs of a pathological condition of the internal organs or of the nervous system. The muscles of the extremities and respiratory muscles were abnormally pale. Histological sections from the diaphragm, intercostal muscles, psoas muscle, calf muscles, thigh muscles, and muscles of the upper arm exhibited a uniform picture. The muscle fibres showed areas undergoing disintegration, the striation was lost, and the fibres were markedly swollen. In some areas the structure of the fibres was obliterated. Single inflammatory cells were observed in affected areas of the musculature. Of the sections examined, the changes appeared to be most advanced in those of the thigh muscles.

CASE A3(G.M.) A male student, born in 1938, had always had well-developed calf muscles. At 7 years the patient had noticed that he tired readily and got out of breath much sooner than his classmates, and later he was exempted from gymnastics because even moderate physical exertion caused dyspnoea, tachycardia, and cramp-like pain in the calves, which became hard and tense. Even on exertion engaging only the arms he became dyspnoeic, tachycardia developed, and the arms soon became weak but not painful. Since that time he had been unable to ascend steps and hills without resting, and on even ground he could only walk a few hundred metres without a rest. The severity of the symptoms varied periodically. While on a cycle tour in September 1960 he became very tired and out of breath, and tachycardia and nausea developed. He nevertheless continued to cycle, but then severe pain occurred in the back, calves, and thighs. During the following six hours he was so tired that he was even unable to stand. Two days later, when he was about to cycle to his doctor, the symptoms recurred, but this time they were more pronounced. Nausea developed into vomiting, he found it difficult to breathe, and he had to be carried home. The following days he was confined to bed and even a few steps were sufficient to cause severe leg pain. The calves were very tender and hard. After a period of rest he could again leave his bed and then soon recovered. During the following six months he was able to tolerate exercise fairly well. The urine had never been dark.

The patient was admitted to the Department of Neurology on 24 January 1961.

Physical status The patient was of ordinary body build and there was no resting dyspnoea or tachycardia. Physical examination of the heart revealed nothing abnormal. Blood pressure was $140 / 90 \mathrm{~mm} . \mathrm{Hg}$.

Neurological status Hypertrophy of the calves was marked, the largest circumference of the calf being $38 \mathrm{~cm}$. The calves were not tender to palpation, but they felt unusually hard. He had no muscular atrophy or pareses. The muscular reflexes and abdominal reflexes were normal on both sides. Babinski's sign was negative bilaterally. Sensibility was normal.

Radiological examination of the lower leg showed hypertrophic musculature without deposition of fat.

Oscillometry At rest the amplitude of the oscillations over the ankles was abnormally large. Over the lower legs and the thighs the amplitude of the oscillations bordered the upper limit of the normal range of variation. The tracing showed normal oscillations over the upper and lower arms. Two minutes and eight minutes, respectively, after slight exercise the amplitude of the oscillations was larger than before exercise.

After the patient had left the Department of Neurology in February 1961 his condition was largely unchanged with short periods of decreased working capacity until the beginning of June 1962, when he fairly suddenly became worse. Even slight physical exertion resulted in dyspnoea and a feeling of heaviness and stiffness of the legs. After a week or so the legs became painful and weak, and he had to stay in bed. For a few days the urine was very dark.

The patient was re-admitted on 19 June 1962.

Physical status There was resting dyspnoea and tachycardia (120 beats/min.) but no cyanosis or oedema. 
Physical examination of the heart revealed nothing abnormal. Blood pressure was $135 / 90 \mathrm{~mm}$. Hg. The patient was afebrile.

Neurological status Hypertrophy of the calves was marked. The calves were abnormally hard and tender to palpation. No muscular atrophy was observed. There was considerable paresis of the legs, especially of the proximal groups of muscles, where the paresis was almost complete. When lying on the floor he could not lift the legs or rise without using his arms and hands. He had no pareses of the arm. The muscle reflexes were normal in the arms, but missing in the legs. The abdominal reflexes were normal. Babinski's sign was negative bilaterally. Sensibility was normal.

Urine analysis No proteinuria was seen, and the sediment was microscopically normal. No myoglobin or porphyrins were demonstrated.

Blood analysis $\mathrm{HCO}_{3}^{-} 18 \mathrm{mEq} . / \mathrm{ml}$., GOT 236 u., GPT 69 u.

The patient recovered fairly soon; the pareses disappeared after a few months and his tolerance of exercise was about the same as before the exacerbation.

CASE B1(K.S.) A housewife, born in 1927, had always had dyspnoea and tachycardia on fairly slight physical exertion. Physical exertion was also accompanied by pain and tenderness of the muscles involved. When at school she was unable to walk quickly over the playground and had to stop and rest until the leg pain had disappeared. Later in life housework caused arm pain, so that she could not manage it alone. On more than moderate exertion she became nauseated and vomited. The symptoms varied in severity during the course of the years, but they were always fairly severe. Two uncomplicated pregnancies resulted in the normal birth of two healthy children, one in 1952 and the other in 1956.

In February 1959 she had a psychosis and was admitted to a mental hospital. She was given insulin treatment in coma doses and improved considerably. During the greater part of insulin treatment she was confined to bed. On completion of treatment she was instructed to be up and about as much as possible to improve her physical condition. Some days later she fell ill with nausea, vomiting, and lumbar pain. She also had severe dyspnoea and tachycardia. After a further week, pain and weakness of the extremities supervened and the urine became dark. She was admitted to the Department of Infectious Diseases, Umeå Hospital, on 29 June and remained there until 24 August. She had resting tachycardia (120 beats $/ \mathrm{min}$.) and dyspnoea (respiratory frequency $30 / \mathrm{min}$.). The proximal musculature of the limbs and the abdominal musculature were practically paralysed. The pareses of the distal groups of the muscles of the extremities were severe but not so pronounced as those of the proximal groups. The muscle reflexes of the extremities were missing, as were the abdominal reflexes. Babinski's sign was negative bilaterally. Sensibility was normal. Electroencephalography showed nothing remarkable.

During the first week she had proteinuria and microscopical haematuria. The highest serum potassium value noted was $5.6 \mathrm{mEq} . / 1$., the lowest serum bicarbonate was $8 \mathrm{mM} . / \mathrm{l}$. The serum creatinine was $3.6 \mathrm{mg} . / 100 \mathrm{ml}$. and the non-protein nitrogen was $200 \mathrm{mg} . / 100 \mathrm{ml}$. The elec-으 trolyte values, the serum creatinine, and the non-protein $Z$ nitrogen gradually became normal. The E.S.R. was $87-37 \cong$ $\mathrm{mm}$. in one hour. No porphyrins were demonstrated in the urine.

By the time the patient left hospital the pareses had practically disappeared, the muscle reflexes in the arms $O$ and the quadriceps reflexes had returned, but the calf $\delta$ reflexes were still missing. A month or so later her condi- $\overline{0}$ tion was roughly the same as before admission. But her $\stackrel{\overrightarrow{2}}{\overrightarrow{2}}$ tolerance to exercise was markedly reduced. She could. only walk for a hundred metres without considerable $\overrightarrow{\vec{F}}$ symptoms and she could not do her housework herself. The urine had never been dark before or during her spell in hospital.

The patient was admitted to the Department of $\frac{\bar{\rho}}{\bar{D}}$ Neurology on 13 March 1961.

Physical status The patient was of ordinary body build, with no resting dyspnoea or tachycardia. Physical ${ }^{\infty}$ examination of the heart revealed nothing remarkable. $\vec{\circ}$ Blood pressure was $160 / 100 \mathrm{~mm}$. $\mathrm{Hg}$.

Neurological status No muscular hypertrophy or $\vec{\omega}$ atrophy was found, or pareses. Ordinary muscle reflexes and abdominal reflexes were equal on both sides. Babinski's sign was negative bilaterally. Sensibility was? normal.

Electrocardiography The resting E.C.G. was normal ir Recordings traced when the patient was standing as we्fli as during or immediately after physical exertion show changes of sympathicotonic type and a high puße frequency.

CASE C1(S.OS.) A male laboratory assistant, born $<$. 1937, during early childhood was sedentary rather thơ응 physically active, but otherwise he appeared health, During the first few years at school he suffered from shof $\overrightarrow{0}$ ness of breath and fatigued readily. On school excursions he found it difficult to keep up with his classmates and always lagged behind because of shortness of breath and tachycardia. When the symptoms were severe he also vomited. At that time he did not complain of pain or weakness of the legs.

In the autumn of 1950 the patient gradually became $\frac{\text { D }}{\mathbb{Q}}$ worse. When cycling to school he became short of breath, the legs became weak, and he sometimes vomited. In $\overline{0}$ October 1950, after a strenuous cycle tour he was exhausted, he vomited, and was too weak to stand up on his legs. After a week's rest in bed the weakness of the? legs disappeared but the following year his tolerance to exercise was considerably reduced. He could not walk up hills, steps, or walk distances of any length on even ground without resting now and then because of dyspnoea, tachy- 3 cardia, and severe weakness of the legs, particularly of the proximal muscles. He had a waddling gait. In the autumn of 1951 he had a new exacerbation, with weakness of the legs, and he often had to go to bed. On 17 October 1951 윽 he was admitted to the Department of Internal Diseases of Örnsköldsvik's Hospital where he stayed until 150 December of that year. He had then resting tachycardia (96 beats/min.) but no dyspnoea and no oedema. Blood $\mathrm{N}$ pressure was $125 / 90 \mathrm{~mm}$. Hg. He had no hypertrophy of $\mathrm{N}$ the calves, which were not tender to palpation and not오 
hard. Moderate pareses were demonstrated in the musculature of the pelvic girdle and in the proximal groups of muscles of the legs. The muscle reflexes were normal and equal on both sides, with the exception of the quadriceps reflexes, which were weak bilaterally. The abdominal reflexes were normal. Babinski's sign was negative bilaterally. Sensibility was normal. When walking up the steps in the hospital the weakness of the musculature of the pelvic girdle increased so much that the patient finally had to draw himself up the steps by the handrail. Electrocardiography showed sinus tachycardia. Routine laboratory examination of the blood and urine revealed nothing remarkable. The E.S.R. was 38-58-22 mm. in one hour. The cerebrospinal fluid appeared normal.

The patient was referred to Serafimerlasarettet, Stockholm, where he was observed from 30 January to 25 February 1952. Physical examination revealed nothing of interest apart from resting tachycardia ( 90 beats $/ \mathrm{min}$.). His neurological status was normal. Examination for thyrotoxicosis yielded no positive findings. Blood studies revealed no abnormality. There was no myoglobinuria or porphyrinuria. Electromyography of the calves showed no definite abnormalities. Electrocardiography showed sinus tachycardia. In tests for physical performance he could only manage 300 k.p.m. for two minutes, during which his legs became tired.

During the rest of the 1950s he felt fairly well, apart from a transient deterioration in 1954. Sometimes he was practically symptom-free and could then play football for an hour at a time without any abnormal shortness of breath or fatigue. As a rule, however, walking up hill caused palpitation and dyspnoea.

In the beginning of June 1962 the patient felt stiffness of the calves when he walked for any distance. These symptoms progressed, and the calves became stiff and very hard, even after a short walk, and a month later he could not walk more than 10 metres or so without symptoms. The lower legs swelled but they were not painful. During this period the urine was very dark for a few days. He avoided all physical exertion and rested much and the symptoms gradually abated. The arms were unaffected. The patient was admitted to the Department of Neurology, Umeå Hospital, on 4 October 1962.

Physical status The patient was leptosomatic. He had resting tachycardia ( 96 beats/min.) but no dyspnoea or oedema. Physical examination of the heart revealed nothing abnormal. The blood pressure was $140 / 80 \mathrm{~mm}$. Hg.

Neurological status The calves were slightly hypertrophied, with largest circumference of $33 \mathrm{~cm}$. The muscles were of normal consistency and were not tender. $\mathrm{He}$ had no pareses. The muscle reflexes of the legs were weak, while those of the arms were normal. The abdominal reflexes were normal. Babinski's sign was negative on both sides. Sensibility normal. The E.E.G. was normal. Electrocardiography showed sinus tachycardia. The B.M.R. varied between $+25 \%$ and $+9 \%$. The P.B.I. was $4 \cdot 6 \gamma \%$.

CASE D2(E.E.) A woman born in 1935, had always had well-developed calves. During childhood she did not play or run about like other children. She soon became breathless and her legs felt tired. As a child she had to walk about 2 kilometres to school and often had to stop on the way 'to take a breath'.

The symptoms, which varied in severity, were never severe before the age of 20 years. In 1955, when she took a job as a kitchen assistant, she found that the work, to which she had not been accustomed, was very heavy. She soon became worse. Even short walks were enough to cause severe palpitation and breathlessness, and she often had to stop and rest because of cramp-like pain in the calves.

From then on the symptoms varied markedly in severity. During long periods she was almost symptomfree, such as during the end of a normal pregnancy in 1961, which terminated in the uncomplicated delivery of a healthy child. During other periods the symptoms were sometimes so severe that she could not even walk upstairs to the first floor of her house. During such periods any work involving the arms caused pain in the biceps and between the shoulder blades as well as weakness of the musculature of the shoulder girdle.

After a strenuous trip to the mountains at the end of April 1962 the patient gradually became worse, and on 30 April she could not even walk; she felt sick and vomited. The slightest movements of the legs caused severe pain. During the next few days marked pareses of the extremities occurred, particularly proximally, and the urine became dark. Resting dyspnoea was so severe that she could barely speak. For a few days she was unable to discharge urine voluntarily.

The patient was admitted to the Department of Neurology, Umeå Hospital, on 9 May 1962.

Physical status She was of ordinary body build. The skin was clammy and the face had a reddish hue. She had moderate resting dyspnoea and tachycardia( 120 beats/ min.), but no oedema. Physical examination of the heart revealed nothing of interest. Blood pressure was $130 / 85$ $\mathrm{mm}$. Hg.

Neurological status Hypertrophy of the calves was noticeable. The calf muscles felt hard and they were very tender. The proximal muscle groups of the limbs were completely paretic; the distal, only slightly. The abdominal musculature was moderately paretic. The patient could hold her head above the pillow for only a short time. She could not sit up in bed. The muscle reflexes were weak or missing. The abdominal reflexes were normal. Babinski's sign was negative bilaterally. Sensibility was normal. Electroencephalography revealed no signs of any pathological condition.

Blood studies Arterial blood was collected during rest: the carbon dioxide tension, the standard bicarbonate concentration, and the $p \mathrm{H}$ were normal as was the oxygen saturation. The concentration of lactic acid and that of pyruvic acid were moderately elevated, $4.3 \mathrm{mM}$./l. and $0.31 \mathrm{mM}$./1., respectively. Venous blood collected in the resting state showed considerably increased concentrations of lactic acid and pyruvic acid in relation to the oxygen tension, $4.5 \mathrm{mM}$./1. and $0.31 \mathrm{mM}$./l., respectively. Oxygen saturation was $75 \cdot 7 \%$.

Other laboratory studies The G.O.T. level was 690-1,490-31 u., G.P.T. 700-280-35 u. Protein was demonstrated in the acute phase. The E.S.R. was 50-65-50 mm. in one hour. $\mathrm{Hb}$ was $78-68-70 \%$; a white 
blood cell count gave $7,000-4,000 / \mathrm{mm}^{3}$; serum creatinine level was $0.5 \mathrm{mg} . / 100 \mathrm{ml}$. and non-protein nitrogen $15 \mathrm{mg} . / 100 \mathrm{ml}$.

Urine analysis Transitory proteinuria and haematuria were seen, but no porphyrins were demonstrated. Myoglobin was identified spectroscopically and determined quantitatively as pyridine haemochromogen $1.3 \mathrm{mg} . / \mathrm{ml}$.

Electrocardiography Sinus tachycardia was recorded, otherwise the tracing was normal.

During her stay in hospital the patient recovered successively and on 13 June 1962 she had only moderate pareses of the proximal muscles of the legs.

During the following few months she continued to improve and she was gradually able to manage her housework without more than slight symptoms. The patient was re-admitted on 5 October 1962 for supplementary examination.

Physical status There was no resting dyspnoea or tachycardia. Physical examination of the heart revealed nothing remarkable. Blood pressure was $130 / 75 \mathrm{~mm}$. $\mathrm{Hg}$. and the E.S.R. $7 \mathrm{~mm}$. in one hour.

Neurological condition The calves were distinctly hypertrophied, with the largest circumference $38.5 \mathrm{~cm}$. They felt hard, but they were not tender to palpation. No muscle pareses were present. The muscle reflexes were normal and equal on both sides. Babinski's sign was negative bilaterally. Sensibility was normal.

CASE E1(E.S.) A woman, born in 1918 , as a child was delicate and did not play and run about like other children. When others played, the patient tried to avoid them in order not to be asked to join in their games. She could not even walk up small hills because of shortness of breath and fatigue. At 7 years she began school and then she could not walk the whole way (1 kilometre) without resting several times because of shortness of breath, palpitation, and leg cramp. The legs also felt weak and heavy. During such periods even cycling for a short time was sufficient to precipitate calf pain, severe dyspnoea, and then she had to stop and rest on the handle-bar for a few minutes before she could continue.

When the patient left school she took a job as a seamstress and ironer. After about six months she had to give up her job because peddling the sewing machine caused severe calf pain, besides which the calves became so tired that after a while she could no longer peddle. When she had been working unusually hard, even ironing proved too strenuous for her: the upper arms became painful and after a short time the arm was so weak that she could not even lift the iron. She returned to her parents' home, where she helped with the housework until she married. The patient reported that her condition had varied substantially since then. She could never walk more than about 200 metres without resting. On a few occasions she accompanied her husband to a nearby lake on a fishing tour. They motored almost up to the lake but the last hundred metres or so the patient had to walk through fairly deep snow. When she got to the lake she was completely exhausted and breathless and her legs were so weak that she could not stand but had to lie down on the ground and rest for 20 minutes. On such occasions she was nauseated and vomited, and often had stabbing pain between the shoulder blades.

During the last trimester of every pregnancy she could $\stackrel{\mathbb{D}}{=}$ hardly walk more than 10 metres without symptoms. O However, she gave birth to three healthy children.

She reported that even light housework was enough to̊ make her short of breath. As soon as she went down intow the cellar to fetch some food from the deep-freeze she was so breathless that she could barely speak. The last few years she had tried to avoid over-exertion. As soon as she noticed the slightest shortness of breath or weakness of. the limbs she rested.

The urine had, as far as she knew, never been dark.

The patient was admitted to the Department of Neurology, Umeå Hospital, on 5 September 1961.

Physical status The patient was thin and had no resting dyspnoea or tachycardia. Physical examination of the heart revealed nothing remarkable. The blood pres-n sure was $180 / 110 \mathrm{mg}$. $\mathrm{Hg}$.

Neurological status The calves were slightly hyper- $\overrightarrow{0}$ trophied (largest circumference $36 \mathrm{~cm}$.). The muscles felthard, but they were not tender. There were no pareses. $\vec{\omega}$ Muscle reflexes were normal and equal on both sides. The abdominal reflexes were normal. Babinski's sign was negative on both sides. Sensibility was normal.

\section{RESULTS}

CLINICAL EXAMINATION Of the 14 patients, eighto were females and six were males. The ages of thepatients at the time of examination varied from 12 Fo응 43 years. The medical history of all the patients was largely the same.

The disease had been noticed during childho and was characterized mainly by poor geneiglo physical condition, moderate physical exertion being. ${ }^{+}$ sufficient to cause fatigue, dyspnoea, and severe palpitation. If the patients did not then rest for a time, stiffness, tenderness, pain, and finally weakness $\overline{\bar{\partial}}$ of the muscles used in exercise occurred as well as

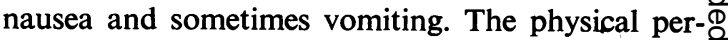
formance varied, however, substantially. During $\overrightarrow{\vec{T}}$ some periods, sometimes for as long as one or more $\frac{0}{3}$ years, but usually for a few weeks or months, their performance was surprisingly good and the patients could lead a fairly normal life as long as they avoided severe physical exertion, especially for any long $\bar{\partial}$ period at a time. On other occasions, sometimes: suddenly and for no apparent reason, sometimes 3 after prolonged but relatively slight physical exertion, the patients experienced periods of such weak- $\frac{\text { 을 }}{3}$ ness that they could barely go for more than a short distance on even ground, and in some cases they even had to rest in bed with their limbs paretic and $\frac{7}{O}$ with severe muscle pain. In nine patients (A1, 3-4; $\mathrm{B} 1-2 ; \mathrm{C1}, 3 ; \mathrm{D2}-3)$ the urine was dark during such $\mathrm{N}$ acute episodes.

Seven (cases A1, 3-4; B1-2; C1; D2) of the patients 워 
had been cared for at hospital during the acute state. The clinical picture of all of them was largely uniform. They had severe resting dyspnoea and tachycardia. Electrocardiography showed sinus tachycardia but no other signs of a pathological condition. The muscles, particularly those of the calves, were hard and very tender. The patients had severe pareses, most pronounced in the legs and then in the proximal groups of muscles. In some patients the abdominal musculature was also paretic. The muscle reflexes were weak or absent. The urine was dark except in one case (C1). In A1, B2, and D2 spectrophotometry revealed myoglobin in the urine. In the other cases the urine was not examined for myoglobin. Blood analysis in the resting state showed a low bicarbonate value (cases A1, A3-4, and B1). In A3 and D2 the concentration of lactate and that of pyruvate was markedly elevated, namely, 3.6 to $4 \cdot 4$ and 0.26 to $0.30 \mathrm{mM} / 1$. respectively. The concentration of potassium was not abnormal with certainty. In cases $\mathrm{A} 4$ and $\mathrm{B} 1$ the non-protein nitrogen was increased. In A3, B2, C1, and D2 the serum transaminases (G.O.T., G.P.T.) were determined, and found to be increased. It is noteworthy that the condition improved without any therapeutic measures other than bed-rest. Even severe or total pareses disappeared within two to three months, at the same time as the muscle reflexes returned. One exception to this rule was case A1. After an acute attack the patient had permanent weakness of the muscles of the pelvic girdle, manifested by a waddling gait, difficulty in rising from the stooping posture or from a low chair without using her hands, etc.

When first seen at the Department of Neurology two of the patients, A1 and D2, were in an acute state. One (A1) died a few days later in hospital. The other (D2) recovered relatively rapidly and the pareses disappeared completely within a few months. She was re-admitted to the Department for supplementary investigation. In case B2 the patient had had a crisis a few months previously and was still convalescent. He had moderate pareses of the proximal groups of muscles of the legs but was otherwise neurologically normal. The remaining patients were in a chronic state. They had no pareses of the extremities, but one (case A4) had slight abdominal muscular pareses. The reflexes were normal. In case A3 the patient was readmitted one and a half years later and then in an acute state with severe pareses and loss of muscle reflexes of the legs. In seven cases (A1-4, D2-3, and E1) there was distinct hypertrophy of the calf (Fig. 1), and the calf muscles were abnormally hard. In three cases (C1-3) the patients probably had hypertrophy of the calves. In none of the cases did radiological examination show pathological deposition of fat in the musculature.

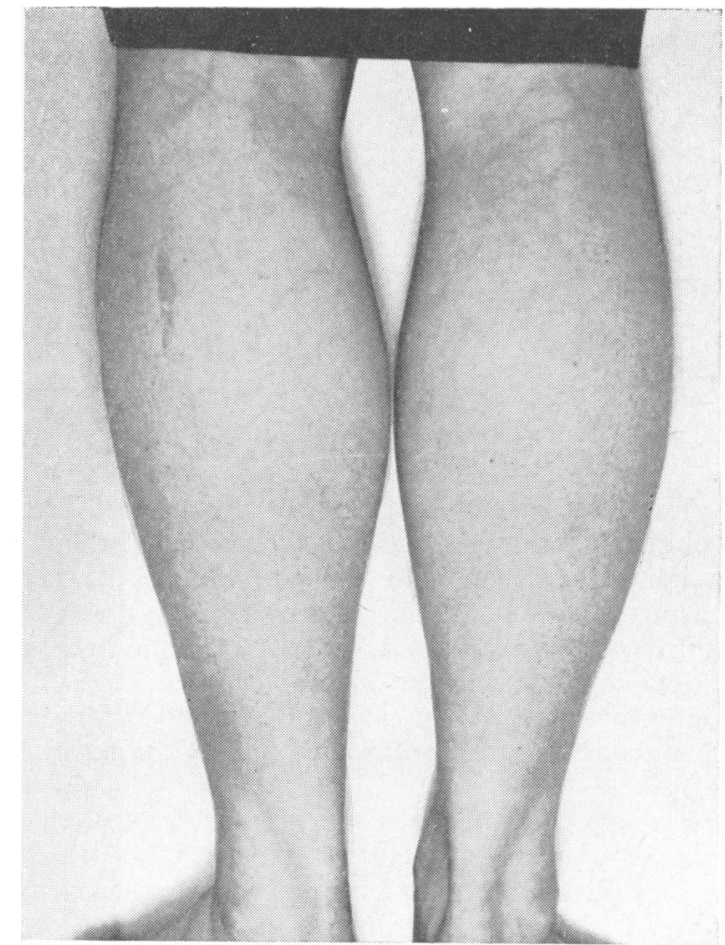

FIG. 1. Case A2. Hypertrophy of the calf muscles.

PATHOPHYSIOLOGICAL INVESTIGATION No tests requiring exertion of the patients were done during the acute state.

EXERCISE TOLERANCE On brief muscle contraction the muscular strength of the patients was, as a rule, normal. On prolonged exercise, such as cycling on the cycle-ergometer, the physical performance was far below normal (Fig. 2). The physical working capacity, $\mathrm{PWC}_{170}$, ranged between 75 and 225 k.p.m./min. for male and female patients against normally about $600 \mathrm{k} . \mathrm{p} . \mathrm{m} . / \mathrm{min}$. for females and 900-1,200 k.p.m./min. for males. The corresponding values for arm exercise were 75-150 k.p.m./min. against normally $300-400$ k.p.m./min. for females and $500-600 \mathrm{k} . \mathrm{p} . \mathrm{m} . / \mathrm{min}$. for males. In contrast to the controls the pulse frequency in most of the patients increased more than 10 beats per minute from the second to the sixth minute of a period of constant exercise intensity. A relative steady state of the pulse rate was thus never reached. After such exercise tests the patients were tired and required a long time to recover. During the 24-hour period after the work tests the urine was collected and studied spectrophotometrically for myoglobin. After the first and most strenuous exercise myoglobin was demonstrated in the urine in case B1. 

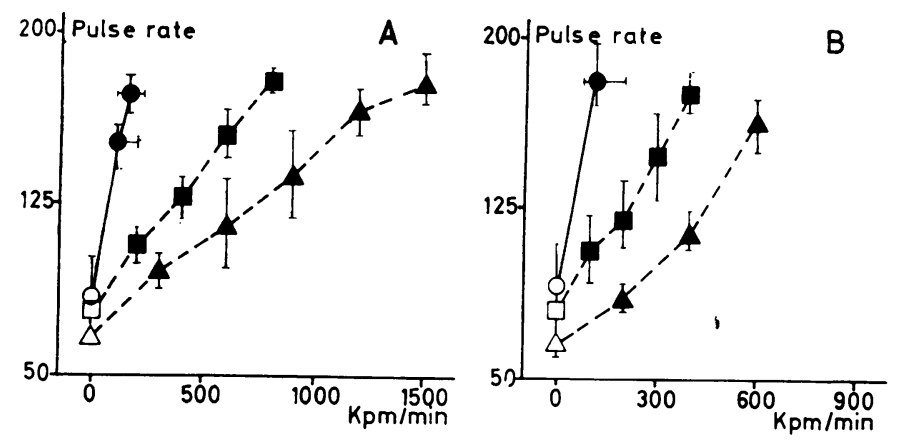

FIG. 2. Mean pulse rate in relation to wor load. Five male and seven female patients $\left(\mathrm{O}^{\prime}\right.$ exercised with the legs (Fig. 2A) and three male and four female patients with the armo (Fig. 2B). They were compared with five female controls $(\square)$ and four male control $(\triangle)$. Open symbols for values at rest and filled symbols for values during exercise. Crosses indicate the range.

The total haemoglobin, blood volume, and heart volume in all cases was largely normal for body weight. The heart volume was normal for total haemoglobin and blood volume. The physical performance was very low relative to the total haemoglobin and heart volume (Table I).

Electrocardiography at rest showed transient changes of obscure significance in two of the patients.

HAEMODYNAMICS, OXYGEN UTILIZATION, CONCENTRATION OF LACTIC AND PYRUVIC ACIDS To investigate the cause of the low physical working capacity cardiac catheterization was done. The heart stroke volume was found to be normal at rest and during leg exercise up to a high pulse rate (Table I). The blood pressure in the general circulation and in the pulmonary circulation was normal. There were no signs of right-to-left or left-to-right shunt.

The utilization of the oxygen transported by the blood to the tissues was normal at rest, the cardiac output in relation to uptake of oxygen and the arteriovenous oxygen difference being normal. On the other hand, the utilization of oxygen durings exercise was low, as reflected in a low arteriovenouso oxygen difference, high oxygen saturation of mixed venous blood in the pulmonary artery (Fig. 3A), an large cardiac output in relation to uptake of oxygers (Table I). The concentration of lactate was largely? normal at rest, but during exercise it increased sub-iv stantially more in relation to the work load in the patients than in the controls (Fig. 3B). Durifgid exercise the concentration of the lactate was markedy high in relation to the slight reduction of oxygen? saturation in the pulmonary artery (Fig. 3C). During exercise the bicarbonate concentration decreasedO largely in proportion to the corresponding increase of lactate concentration but returned to norne within three hours (Table II).

Abnormal regulation of the peripheral circulation was demonstrated more distinctly in the venous ${ }^{ \pm}$

TABLE I

COMPARISON BETWEEN PATIENTS STUDIED BY HEART CATHETERIZATION AND CONTROLS

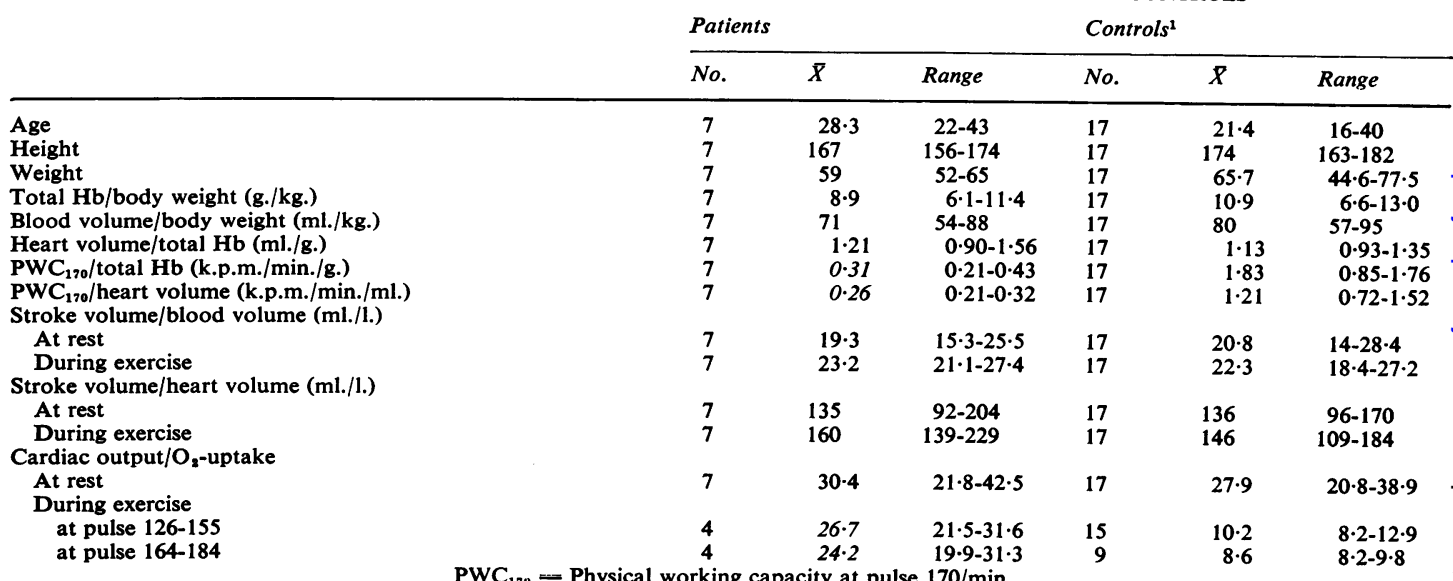



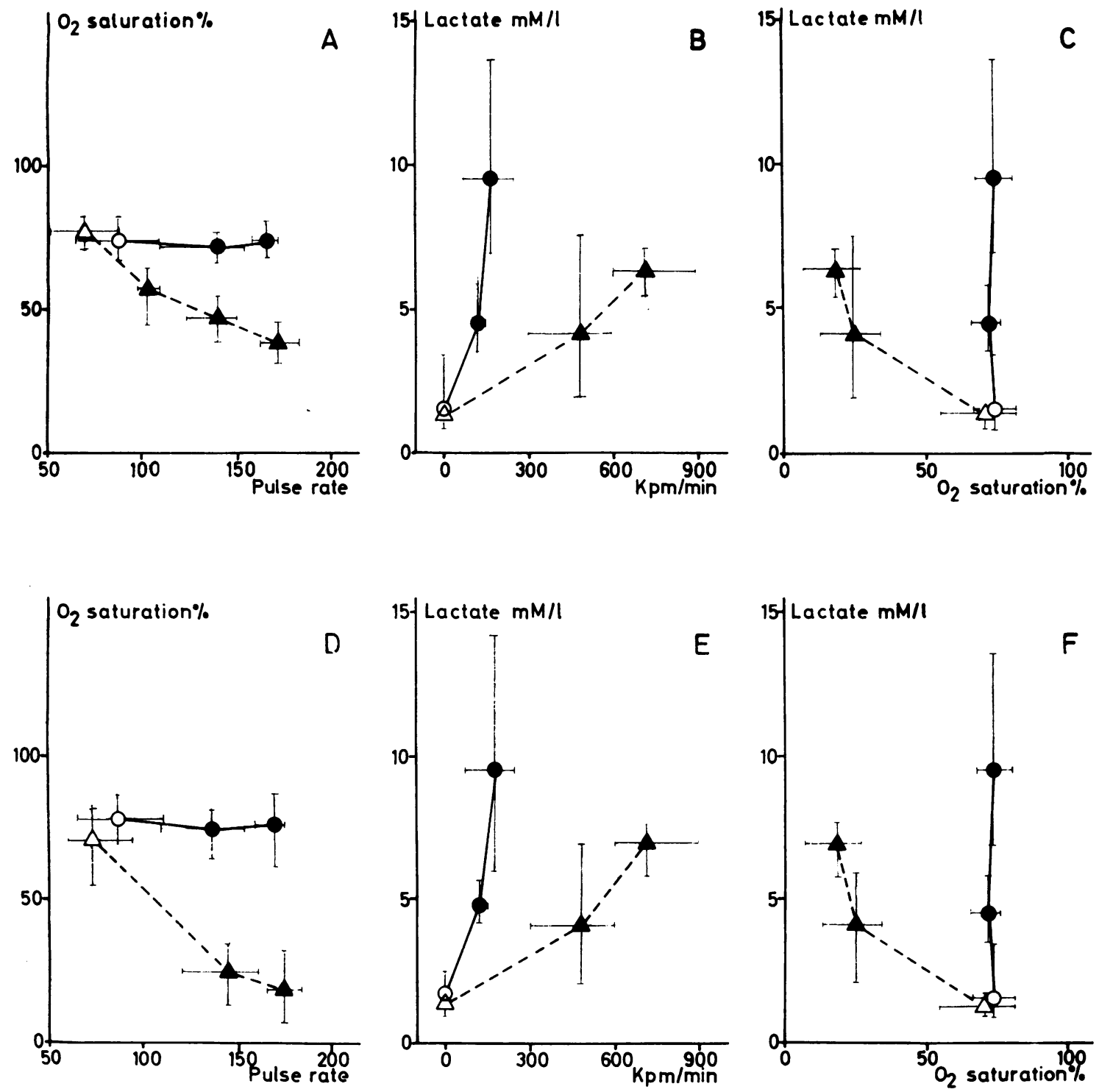

FIG. 3A-C. Oxygen saturation and lactate concentration of mixed venous blood at rest and during leg exercise in two male and five female patients $(O)$ and controls $(\triangle)$. Open and filled symbols indicate mean values; crosses, the range.

FIG. 3A. Oxygen saturation related to pulse rate in patients compared with 14 male and three female controls from Holmgren, Jonsson, and Sjöstrand (1960).

FIG. 3B. Lactate concentration related to work load in patients compared with one female and five male controls from Carlson and Pernow (1959). Two of the controls (one male and one female) were examined under the same conditions as the patients while four controls cycled with one leg in the sitting position. In the four male controls and in the group $\mathrm{N}_{2}$ of Fig. $3 C$ the lactate concentration of the arterial blood and finger prick blood was taken to equal that of mixed venous blood (cf. Holmgren and Ström, 1959).

FIG. 3C. Lactate concentration related to $\mathrm{O}_{2}$ saturation in patients and controls. The normal $\mathrm{O}_{2}$ saturation values were obtained from Holmgren et al. (1960) and normal values for lactate concentration (group $N_{2}$ ) from Holmgren and Ström (1959) at comparable pulse rates, the two control groups being almost equal with regard to mean work capacity.

FIG. 3D-F. Same relations as in Fig. 3A-C for femoral venous blood in three male and five female patients, and the same controls as in Fig. $3 B$. 
blood from the exercising limbs than in mixed venous blood from the pulmonary artery.

In the femoral vein the oxygen saturation and the concentration of lactate were normal during rest. During leg exercise the degree of saturation in the femoral vein was largely unchanged and thus higher than normal in relation to pulse frequency (Fig. 3D) and work load (see Figs. 2 and 3D). The lactate concentration increased more than normally in relation to the work performed and the oxygen saturation of the blood in the femoral veins (Figs. 3E and $F$ ).

The resting oxygen saturation and the concentration of lactate in the axillary vein were normal. During arm exercise the oxygen saturation of the blood in the axillary vein was higher than in the controls in relation to pulse frequency and work performed (see Figs. 2 and 4A). The concentration of lactate was higher than normal in relation to the work load and the saturation of the oxygen in the axillary vein (Figs. 4B and C). In a superficial arm vein, on the other hand, the oxygen saturation of the blood during almost maximal arm exercise was the same in the patients and controls (Fig. 4D), while the concentration of lactate in the patients was higher than in the controls in relation to work load (Fig. 4E). The relation between the lactate concentration and the saturation of oxygen in the superficial arm vein during almost maximal exercise was, however, roughly equal in patients and controls (Fig. 4F).

In practically resting legs the oxygen saturation of the blood in the femoral vein decreased during arm exercise in patients in the same way as in the controls (Fig. 4G), while the concentration of the lactate was higher in patients than in the controls in relation to work load (Fig. 4H). In relation to the oxygen saturation of the blood in the femoral vein the lactate concentration was largely the same in both groups (Fig. 4I).

In three patients the concentration of pyruvic acid $\stackrel{\mathbb{Z}}{=}$ was studied in arterial and venous blood. During rest the concentration of the pyruvic acid was normal. In blood from the exercising limbs the con- 0 centration of the pyruvic acid during and after exercise was abnormally high for the work load and $\stackrel{\rho}{I}$ for the lactate concentration (Table II).

PULMONARY FUNCTION AND VENTILATION DURING EXERCISE The lung volumes were normal, as was ventilation and the distribution of the alveolar gas. The uptake of oxygen in the patients during leg exercise increased at a normal rate for the intensity $\frac{\bar{\sigma}}{7}$ of exercise (see Astrand, 1960). During exercise $\stackrel{\nabla}{\Phi}$ ventilation was increased in relation to the uptake of oxygen and the work load and the carbon dioxide ${ }^{\infty}$ tension in the arterial blood were low (Table II).

ELECTROMYOGRAPHIC INVESTIGATION IN THE CHRONIC $\vec{\omega}$ STATE In most patients electromyography after rest showed a higher percentage frequency of polyphasic action potentials with thin components than in controls. They tended to occur in circumscribed areas of the musculature. The insertion activity was normal. The degree and distribution of the electrof myographic changes are given in Tables III and I\$, 음

Table III includes controls matched with patien concerning the muscles examined. The difference $\bigcirc$ between the two groups in the number of polyphasif $\frac{9}{0}$ action potentials is statistically significant, but n\& the difference in the mean duration.

In some patients the above mentioned signs $\vec{f}$

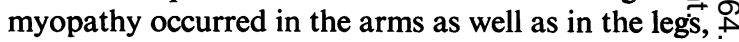
both distally and proximally. In a few patients no changes suggesting myopathy could be demonstrated with certainty (Table IV).

TABLE II

LACTATE, PYRUVATE, STANDARDIZED BICARBONATE CONCENTRATIONS, AND $\mathrm{P}_{\mathrm{CO}_{2}}$ OF ARTERIAL BLOOD AT REST AND DURING LEG EXERCISE OF VARYING INTENSITY

\begin{tabular}{|c|c|c|c|c|c|c|c|c|}
\hline & & $\begin{array}{l}\text { No. of } \\
\text { Patients }\end{array}$ & $\begin{array}{l}\text { Pulse } \\
\text { Rate } \\
\text { (beats/min.) }\end{array}$ & $\begin{array}{l}\text { Work } \\
\text { Intensity } \\
\text { (k.p.m./min.) }\end{array}$ & $\begin{array}{l}\text { Lactate } \\
(m M . / l .)\end{array}$ & $\begin{array}{l}\text { Pyruvate } \\
(m M . / l .)\end{array}$ & $\begin{array}{l}\text { Standard } \\
\text { Bicarbonate } \\
(m M . / l .)\end{array}$ & $\begin{array}{c}\mathrm{PCO}_{2} \\
(\mathrm{~mm} . \mathrm{Hg})\end{array}$ \\
\hline Exercise at moderate pulse rate & $\begin{array}{l}\text { Mean } \\
\text { Range }\end{array}$ & 5 & $\begin{array}{l}141 \\
110-155\end{array}$ & $\begin{array}{l}120 \\
100-150\end{array}$ & $\begin{array}{l}5 \cdot 1 \\
3 \cdot 5-6 \cdot 4\end{array}$ & $0.71(n=1)$ & $\begin{array}{l}18 \\
14-22\end{array}$ & $\begin{array}{l}31 \\
26-34\end{array}$ \\
\hline Exercise at high pulse rate & $\begin{array}{l}\text { Mean } \\
\text { Range }\end{array}$ & 6 & $\begin{array}{l}169 \\
161-176\end{array}$ & $\begin{array}{l}171 \\
75-250\end{array}$ & $\begin{array}{l}8 \cdot 6 \\
6 \cdot 7-13 \cdot 6\end{array}$ & $\begin{array}{l}1.09(n=2) \\
0.65-1.52\end{array}$ & $\begin{array}{l}14 \\
11-18\end{array}$ & $\begin{array}{l}27 \\
21-32\end{array}$ \\
\hline 3 hours after work & $\begin{array}{l}\text { Mean } \\
\text { Range }\end{array}$ & 4 & & & & & $\begin{array}{l}24^{1} \\
32-18\end{array}$ & \\
\hline 24 hours after work & $\begin{array}{l}\text { Mean } \\
\text { Range }\end{array}$ & 8 & & & & & $\begin{array}{l}23^{1} \\
26-20\end{array}$ & \\
\hline
\end{tabular}

${ }^{1}$ Venous blood. 

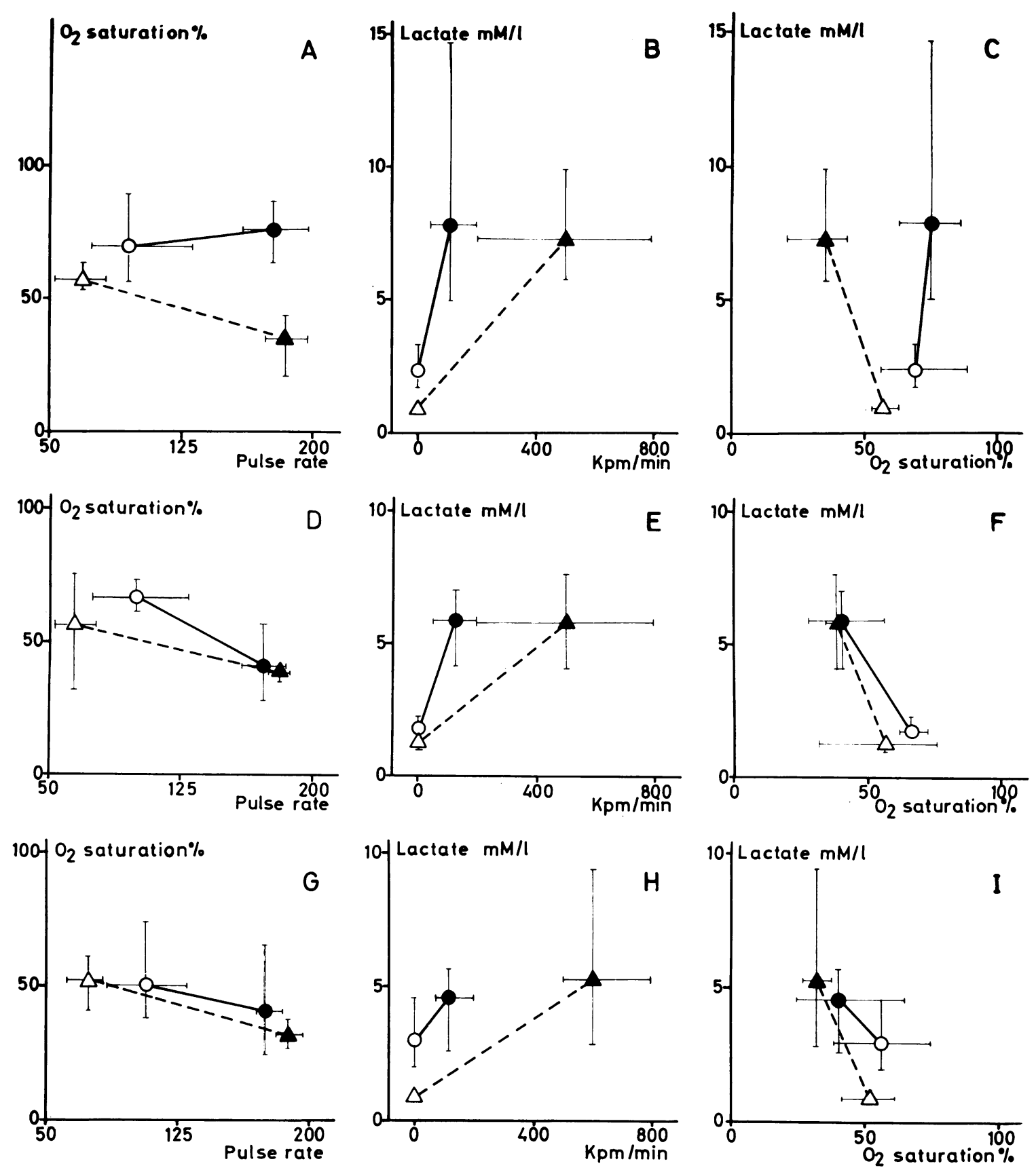

FIG. 4A-I. Oxygen saturation and lactate concentration at rest and during arm exercise in patients and controls (symbols as in Fig. 3).

FIG. 4A-C. Same relations as in Fig. 3A-C for axillary venous blood in three male and four female patients and three male and one female controls.

FIG. 4D-F. Same relations as in Fig. 3A-C for blood from a superficial forearm vein in three male and two female patients and two male and one female controls.

FIG. 4G-I. Same relations as in Fig. 3A-C for femoral venous blood from two male and three female patients and three male controls. 
TABLE III

FREQUENCY OF TETRAPHASIC AND POLYPHASIC ACTION POTENTIALS AND DURATION OF ACTION POTENTIALS IN PATIENTS AND CONTROLS

\begin{tabular}{ll} 
Case & Muscle \\
& \\
\hline A2 & Vastus, lat. et med. \\
C1 & Vastus, lat. et med. \\
D2 & Vastus, lat. et med. \\
E1 & Vastus, lat. et med. \\
A3 & Biceps \\
B1 & Biceps \\
D3 & Biceps \\
A4 & Tibialis anticus
\end{tabular}

$\begin{array}{llll}\text { Total No. of } & \text { Tetraphasic } & \text { Polyphasic } & \text { Duration }^{1} \\ \text { Potentials } & \text { Potentials } & \text { Potentials } \\ & (\%) & (\%) & \end{array}$

Mean, 8 patients

Tibialis anticus

\begin{tabular}{|c|c|c|c|}
\hline 204 & $8 \cdot 3$ & 6.9 & $8 \cdot 3$ \\
\hline 124 & 12.9 & $16 \cdot 1$ & $7 \cdot 8$ \\
\hline 117 & 9.4 & $5 \cdot 1$ & $7 \cdot 9$ \\
\hline 140 & 6.4 & $4 \cdot 3$ & $7 \cdot 6$ \\
\hline 197 & $16 \cdot 3$ & $9 \cdot 2$ & 6.5 \\
\hline 76 & $23 \cdot 7$ & $18 \cdot 4$ & $6 \cdot 3$ \\
\hline 125 & 9.6 & 5.6 & $5 \cdot 7$ \\
\hline 148 & $15 \cdot 5$ & $13 \cdot 5$ & $7 \cdot 6$ \\
\hline $141 \cdot 4$ & $12 \cdot 8$ & 9.9 & $7 \cdot 2$ \\
\hline \multirow[t]{2}{*}{$116 \cdot 0$} & $10 \cdot 5$ & $4 \cdot 5$ & $7 \cdot 3$ \\
\hline & $\begin{array}{c}2 \cdot 3 \\
<0.05\end{array}$ & $\begin{array}{c}5.4 \\
<0.01\end{array}$ & $\begin{array}{l}-0.1 \\
<0.9\end{array}$ \\
\hline
\end{tabular}

${ }^{1}$ The duration has been calculated as the mean of the first 100 action potentials collected.

4 Vastus, lat. et med.

3 Biceps

1 Tibialis anticus

TABLE IV

DISTRIBUTION OF ELECTROMYOGRAPHIC CHANGES AT REST

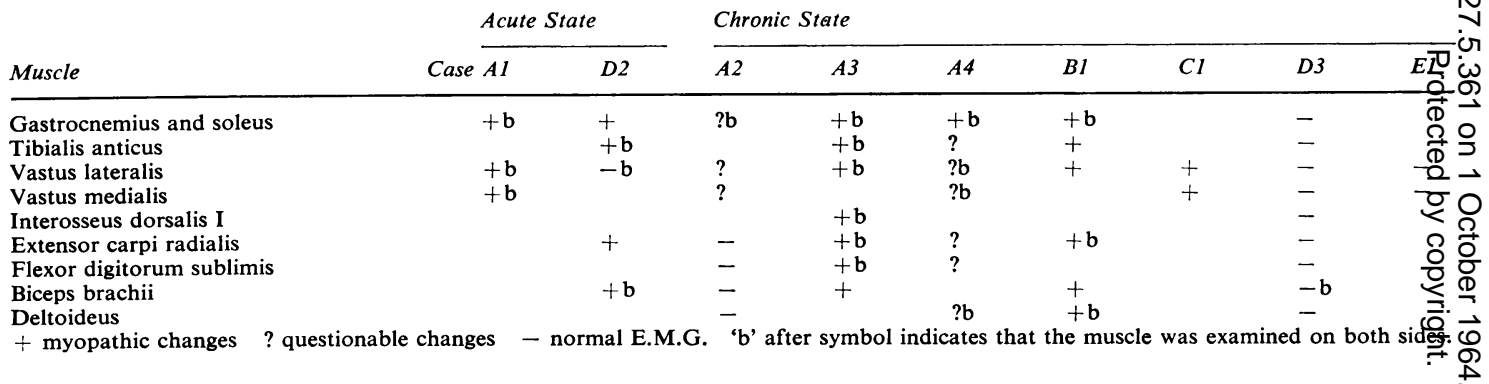

Electromyography before and after exercise was done in six patients (cases A2-3, C1, D2-3, E1) and in a corresponding number of controls. The work was performed as a work test on a cycle-ergometer. On examination of the brachial biceps muscle the patients cranked with their arms.

In the patients as well as in the controls the number of polyphasic action potentials increased significantly during exercise $(p<0.001$ in the patients and $p<0.01$ in the controls). The number of tetraphasic action potentials increased, probably significantly $(\mathrm{p}<0.02)$, in the patients, but not significantly in the controls. The mean duration of the action potentials decreased in the patients $(p<0.01)$ and probably significantly also in the control group $(\mathrm{p}<0.05)$.

The number of polyphasic action potentials increased significantly more in the patients than in the controls, but no other statistically significant differences were observed (Table V). It should be mentioned that the degree of exertion, as judged by the pulse frequency, was larger in the controls than in the patients and that the work performed waso several times larger in the control group (Table V).

One patient (B1) was not tested on the cycleergometer but instead stood repeatedly raising hero toes and heels with the arms hanging passively. Sheop could do this only 25 times and then had a pulse frequency of 168 beats/min. In the tibialis anticus? muscle the number of tetra- and polyphasic action potentials increased, as in the other patients. In the brachial biceps muscle which had not worked no. increase occurred.

The action potentials were collected from 15 tơ⿱ 20 minutes after the end of exercise and continued? for a further 20 minutes. One of the patients (E1) was studied again two and a half hours after the encP of the exercise. She still had a markedly increased number of polyphasic action potentials. Fou patients (A2, C1, D2, D3) were studied four hours after the end of the exercise. In three of them the number of polyphasic action potentials was the samo as before exercise and remained so at examination the following day. In the fourth patient (C1) thes 
TABLE V

ELECTROMYOGRAPHIC CHANGES IN PATIENTS AND CONTROLS AFTER EXERCISE ${ }^{1}$

\begin{tabular}{|c|c|c|c|c|}
\hline & Six Patients & Six Controls & $\begin{array}{l}\text { Difference } \\
\text { Patients-Controls }\end{array}$ & $p$ \\
\hline $\begin{array}{l}\text { Increase in percentage frequency of } \\
\text { tetraphasic action potentials } \\
\text { polyphasic action potentials }\end{array}$ & $\begin{array}{l}5.87 \\
6.48\end{array}$ & $\begin{array}{l}1 \cdot 73 \\
2 \cdot 87\end{array}$ & $\begin{array}{l}4 \cdot 14 \\
3 \cdot 61\end{array}$ & $\begin{array}{l}>0.05 \\
<0.01\end{array}$ \\
\hline Decrease in mean duration of action potentials (msec.) & 0.98 & 0.68 & $0 \cdot 30$ & $>0.3$ \\
\hline $\begin{array}{l}\text { Mean pulse frequency (beats/min.) during maximum } \\
\text { physical performance } \\
\text { Range }\end{array}$ & $\begin{array}{l}176 \\
166-186\end{array}$ & $\begin{array}{l}190 \\
174-199\end{array}$ & - & - \\
\hline $\begin{array}{l}\text { Mean of highest work load performed (k.p.m./min.) } \\
\text { Range }\end{array}$ & $\begin{array}{l}158 \\
100-200\end{array}$ & $\begin{array}{l}900 \\
600-1,200\end{array}$ & - & - \\
\hline $\begin{array}{l}\text { Mean lactic acid concentration (mM./1.) in arterial blood during } \\
\text { exercise at the highest work load performed } \\
\text { Range }\end{array}$ & $\begin{array}{l}8 \cdot 7 \\
6 \cdot 1-10 \cdot 9\end{array}$ & $\begin{array}{l}7 \cdot 6 \\
5 \cdot 4-10 \cdot 4\end{array}$ & - & - \\
\hline
\end{tabular}

${ }^{1}$ The vastus medialis et lateralis muscles were examined in four patients and in four controls after leg exercise and the brachial biceps muscle in two patients and in two controls after arm exercise.

number of polyphasic action potentials was still increased, but the following day the number had decreased to the level it had before the exercise.

ELECTROMYOGRAPHIC INVESTIGATION IN THE ACUTE STATE Two patients (cases A1 and D2) were examined in the acute state, the former a few days before she died. In addition to an increased number of polyphasic action potentials there were in case A1 large areas of electrically inactive muscle tissue, where no voluntary activity could be demonstrated or where only indistinct units could be seen of the type observed when the needle is at a distance from active motor units. In case D2 no such inactive areas could be demonstrated with certainty.

The insertion activity in case D2 showed numerous fibrillation and sharply rising positive insertion potentials, sometimes rising to a brief 'dive bomber phenomenon' in several of the muscles studied. When this patient was re-examined after the acute stage had passed off the insertion activity was normal. In case A1 the insertion activity was sparse.

MUSCLE BIOPSY Biopsy specimens excised from thigh and leg muscles during the acute stage (cases A1, A3, B1, D2) showed widespread necrosis and regeneration of the muscle fibres (Fig. 5). At most one fourth of the muscle fibres were of normal appearance. Other muscle fibres were in various stages of acute degeneration with hyalinization, vacuolation, granulation, and fragmentation. Entire segments of varying length of some muscle fibres had disappeared. In and around the degenerated fibres were fairly numerous lymphocytes, monocytes, macrophages as well as single eosinophilic leucocytes, sometimes grouped in clusters but without any tendency to accumulate preferentially around the vessels. Signs of regeneration were seen in the form of many fibres of varying diameter with basophil cytoplasm and proliferating rows of large sarcolemmal nuclei, often showing distinct vacuoles. There was no substantial increase in the amount of fat or connective tissue. The blood vessels and nerves were of normal appearance.

In the chronic stage (cases A3-4, B1-2, C1, 3, D3)

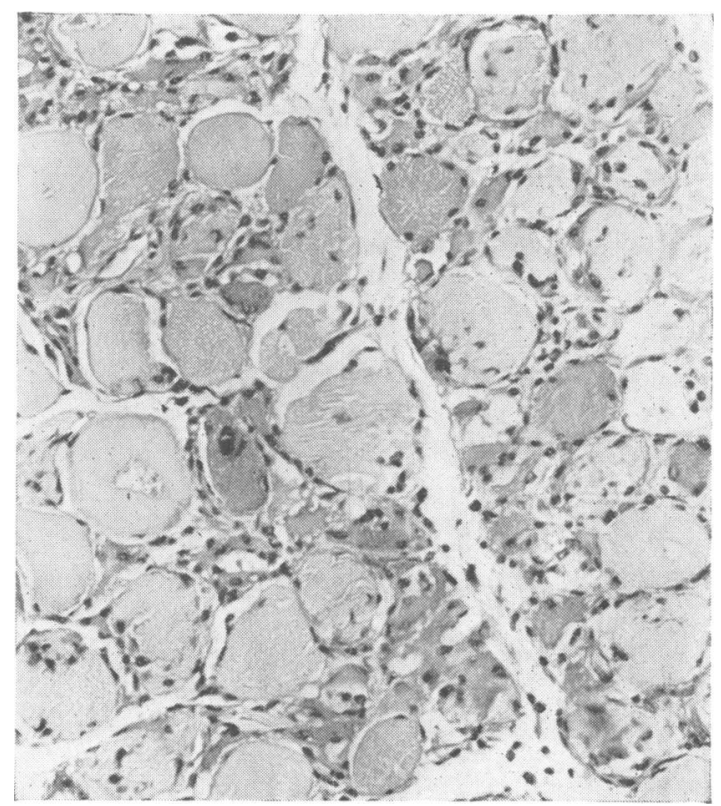

FIG. 5. Case D2 in an acute state. Section from the left gastrocnemius muscle. Most of the muscle fibres show severe necrosis resembling Zenker's degeneration. Phagocytosis of degenerated fibres. Regenerating fibres are seen. Hematoxylin and eosin $\times 192$. 


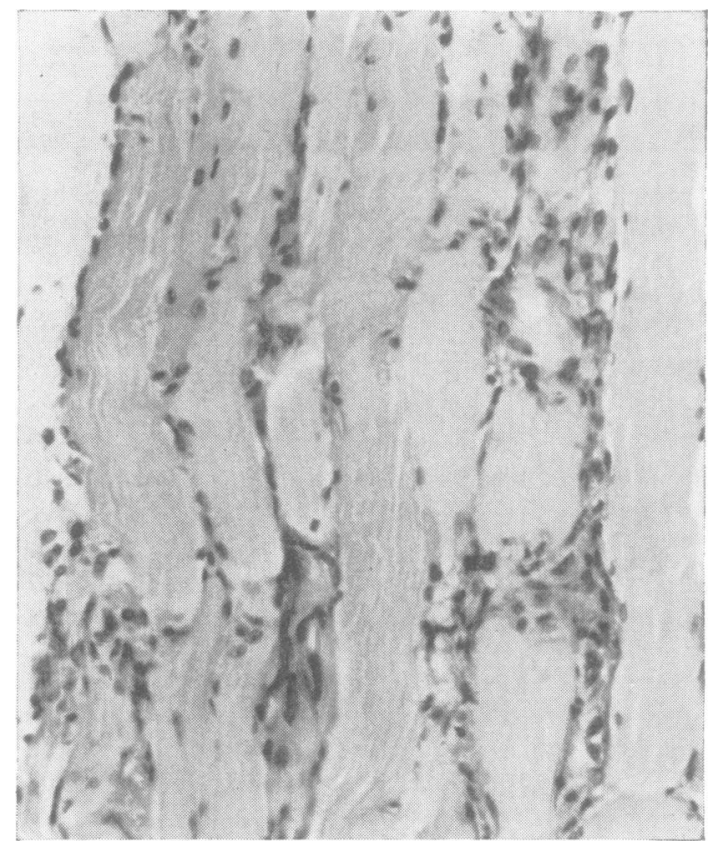

FIG. 6. Case A4 in an acute state. Section from the left gastrocnemius muscle showing acute degeneration of muscle fibres. Haematoxylin and eosin $\times 470$.

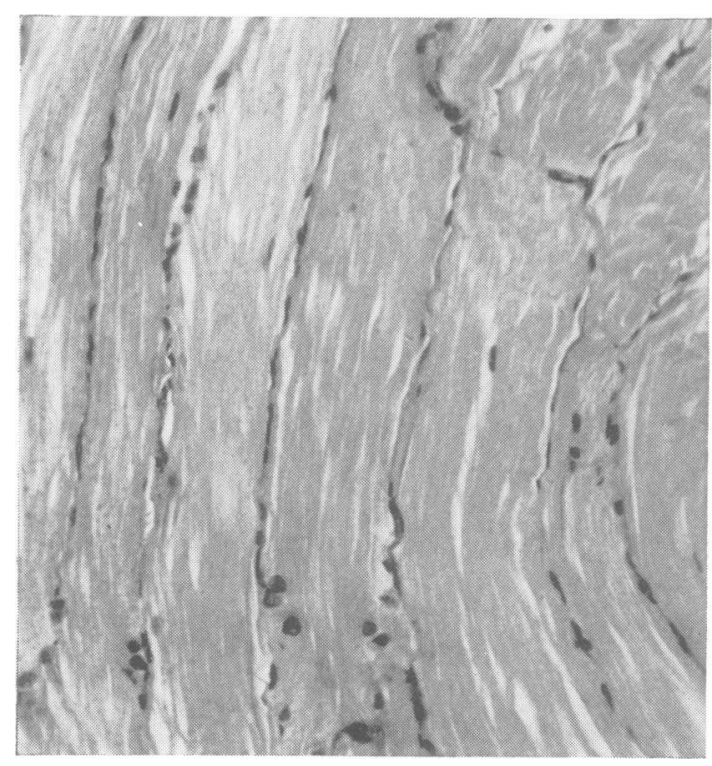

FIG. 7. Case A4, one and a half years later, in a chronic state. Section from the left gastrocnemius muscle. The muscle has a normal appearance. Haematoxylin and eosin $\times 470$. the histological appearance of the muscles was largely normal. In three of the cases, however, a fewष fibres were undergoing acute degeneration and had been invaded by macrophages and lymphocytes.? Single areas of regeneration were also seen. The endomysial and perimysial connective tissue was normal. Figures 6 and 7 show biopsy specimens from the muscle of the same patient during the acute and $\frac{\overline{2}}{\mathrm{z}}$ chronic states. It is seen that the muscle has completely recovered.

Staining for glycogen by the Best carmine method $\overrightarrow{\vec{F}}$ showed a normal quantity of stainable glycogen. ${ }^{1}$

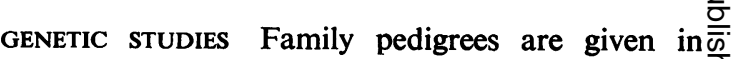
Figures 8-12. Most of the closest relatives of the $\widehat{D}$ patients were studied neurologically. The parents of patients A1-4 were also studied regarding working ${ }^{\mathcal{S}}$ capacity and total haemoglobin, as well as being. examined electromyographically. No further cases $\overrightarrow{-}$ of the disease or muscle affection other than hyper- $\omega$ trophy of the calves could be demonstrated in the various families.

In families $\mathbf{A}, \mathbf{B}$, and $\mathbf{C}$ there were no consanguin- $\hat{N}$ eous marriages in the generations studied. In family $\mathrm{v}$ $D$ there were two second-cousin marriages generation IV. The parents of E1 were first cousints. In this family, however, there was a high inciden e을 of consanguineous marriages (Fig. 12).

Our patients probably had a gene defect, most $ᄋ$ likely transmitted by a monohybrid autosom $1 \frac{\circ}{0}$ recessive mode of inheritance.

The observed number of affected sibs was 1 according to the a priori method, with probability $0 \cdot 25$, the expected number is $9 \cdot 8 \pm 2 \cdot 1$ (Table VI). + Using Weinberg's sib method the number of sibs of $\square$ the affected is 80 and the number of affected sibs of the affected 32. which gives a mendelian ratio of $40 \pm 9 \cdot 3 \%$. The results, however, do not argue against the assumption of a monohybrid autosomal $\stackrel{\unrhd}{\unrhd}$ recessive mode of inheritance with a $100 \% \overrightarrow{\overrightarrow{0}}$ penetrance.

Patients A1-4, like the two healthy sibs, the mother and several of her closest relatives, had hypertrophy? of the calves (Fig. 8). Patients D2-3 and E1 also had hypertrophy of the calves with certainty, and C1-3 possibly had slight hypertrophy. None of the other members of families D, E, and C had hypertrophy of the calves. Hypertrophy of the calves was not seen in any of the members of family $B$.

\section{DISCUSSION}

Obvious similarities were noted between the clinical $\stackrel{7}{=}$ picture of our cases and that of some of the cases $\mathrm{N}$

'Biopsy specimens were examined by Dr. Karl-Erik Åström, Institute N of Pathology, Sabbatsberg's Hospital, Stockholm. 
FIG. 8. Pedigree of family $A$.

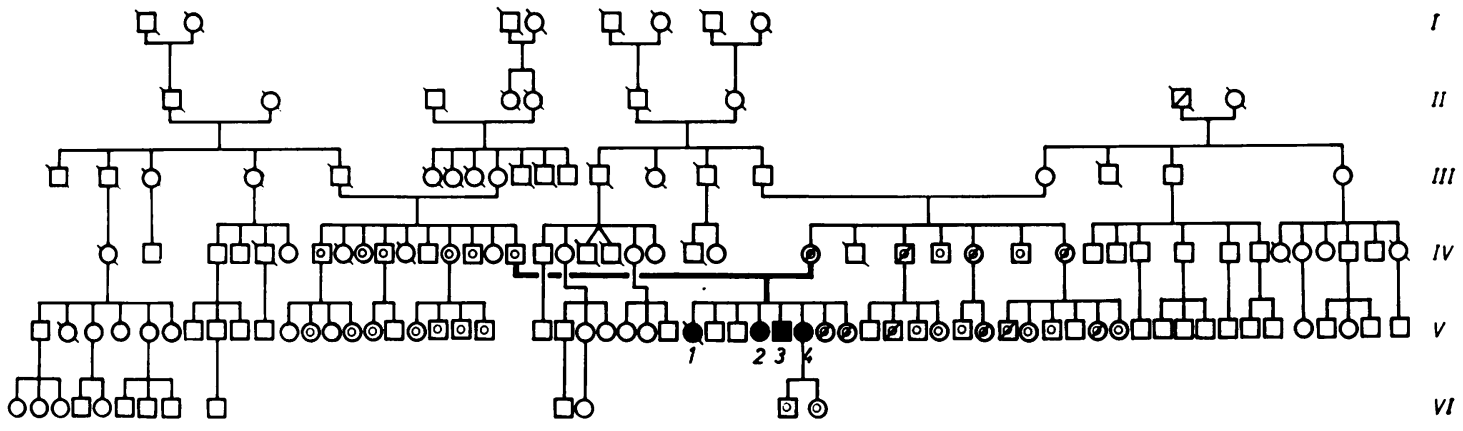

FIG. 9. Pedigree of family $B$.

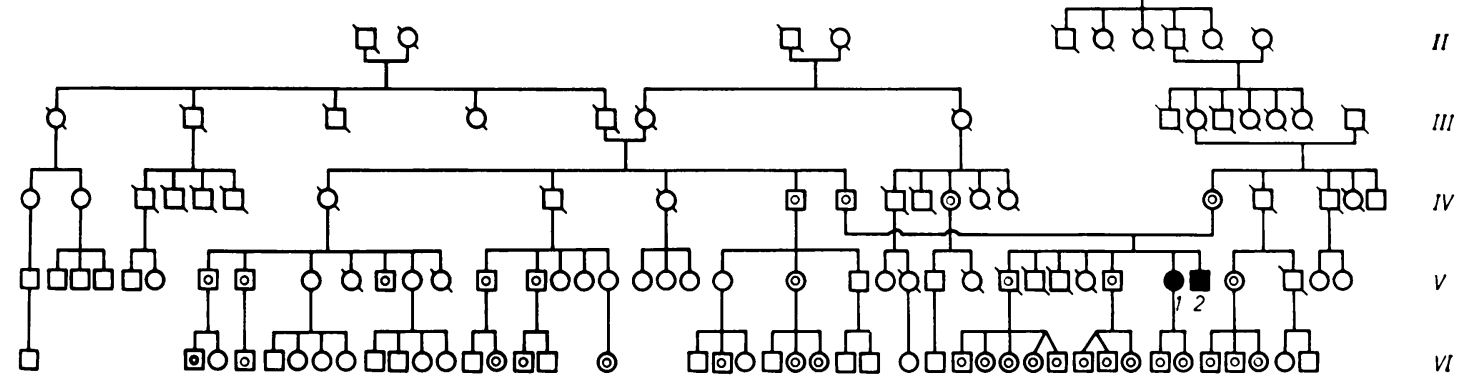

FIG. 10. Pedigree of family $C$.

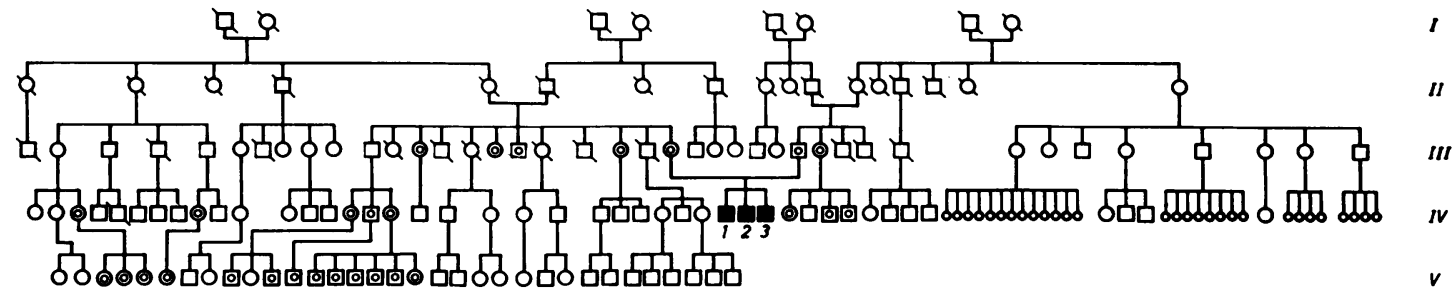

FIG. 11. Pedigree of family $D$.

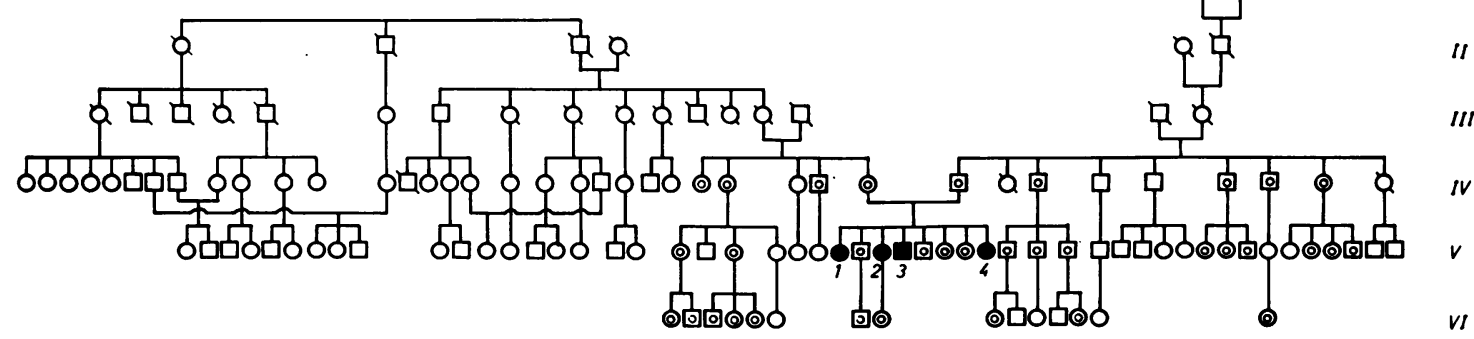

FIG. 8-12.

- sex unknown.

$\square \quad$ male, not affected, not examined.

$\bigcirc \quad$ female, not affected, not examined.
(ㅇ not affected, examined.

$\square$ affected, examined.

$\square Q$ dead at time of publication.

$\square \oslash$ not affected, hypertrophy of the calves. 
FIG. 12. Pedigree of family $E$.

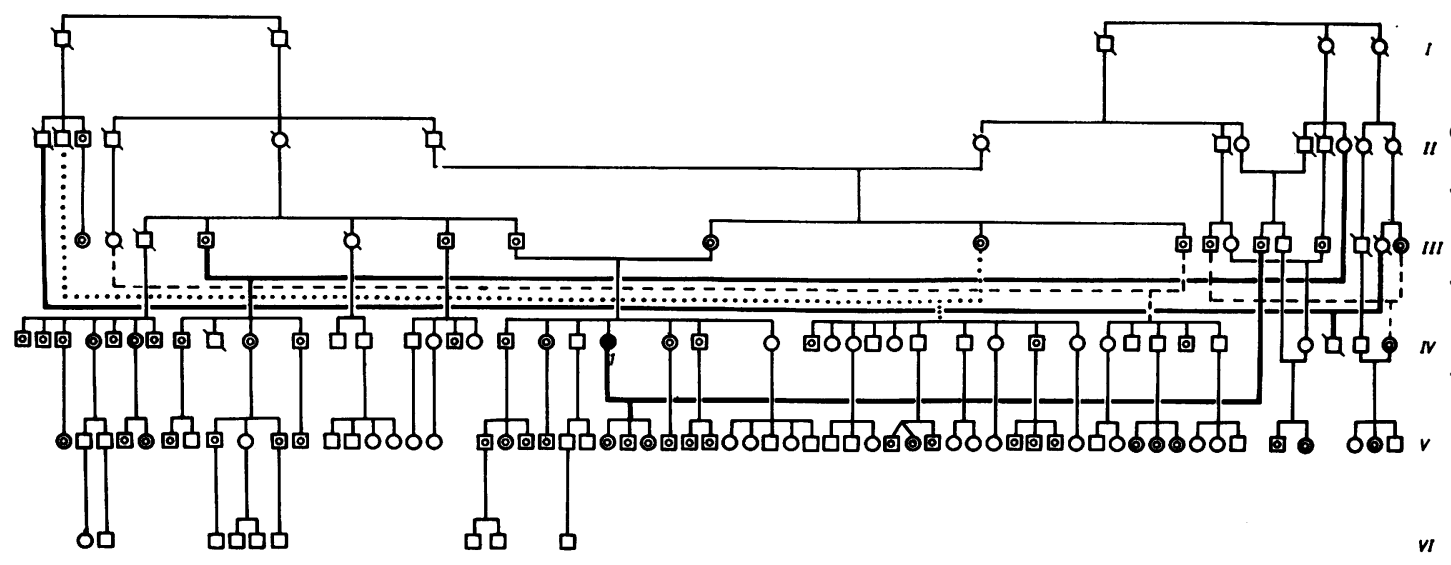

TABLE VI

MENDELIAN ANALYSIS

Number of Children

\begin{tabular}{lcc}
\hline Total & Affected & $\begin{array}{l}\text { Expected } \\
\text { No. Affected }\end{array}$ \\
\hline 33 & 14 & $9 \cdot 781$ \\
published under the name of idiopathic paroxysmal \\
myoglobinuria or its synonyms.
\end{tabular}

Korein et al. (1959) classified the 45 cases of idiopathic paroxysmal myoglobinuria published up to 1959 in two groups according to whether the symptoms were precipitated by physical exercise or by other factors. These two groups, which were equally large, differed clinically in several respects. In the former group (group I) the disease usually made its first appearance at 15-20 years of age and was chronic; it persisted for years or decades with frequent exacerbations characterized by muscle pain, muscle tenderness, pareses, and myoglobinuria. Some of the patients were symptom-free during remissions, while others were disabled by constantly recurrent muscle pain during exercise. The mortality was fairly low. The cause of death was respiratory paralysis, renal insufficiency, or circulatory failure. In the latter group (group II) the onset was acute, often in association with respiratory tract or intestinal infection, and the mortality was high. Nearly all of the patients had had the disease from childhood and then only had one or two attacks. Korein et al. (1959) suggested the name 'toxic myoglobinuria' for this group. Cases published later fit this classification. Eight of them (Daugherty, Kaye, and Mathieson, 1959; Gillett, 1959; Javid, Horowitz, Sanders, and Spaet, 1959; Phillippi, Jones, and Kenoyer, 1960; Wheby and Miller, 1960; Farmer, Hammack, and
Frommeyer, 1961; Kontos, Harley, Wasserman, Kelly, and Magee, 1963) fall within group I, a (Haase and Engel, 1960) within group II.

Group I resembles our cases in that the symptorim were precipitated by muscular activity. However, the poor physical performance during remissions in the published cases appears to be due to local muscle + symptoms, while in our patients the physical performance was reduced mainly by fatigue, palpitation, and dyspnoea. Local muscle symptoms did not appear until the patients had exerted themselves and continued to work despite the feeling of fatigue. This $\frac{\mathbb{Q}}{2}$ was also noted during exercise on the bicycle-ergo- $\underset{F}{\Rightarrow}$ meter while the patients were in hospital. Even a low work load of some minutes' duration was sufficient to cause fatigue, exhaustion, and hyperventilation, and to raise the pulse frequency to 170 beats $/ \mathrm{min}$. or more. They then had no limb pain or pareses but were nevertheless unable to continue cycling. Dyspnoea and palpitation had periodically been so pronounced that heart disease and occasionally also thyrotoxicosis had been suspected. In the acute state the patients had severe tachycardia and hyperventilation even at rest, as in exacerbations of idiopathic paroxysmal myoglobinuria (Hed, 1955; Wheby and Miller, 1960).

Tolerance to exercise in our cases varied and gave $\mathcal{O}$ the disease a characteristic fluctuating course with exacerbations and remissions but without any true 
progress. The only explanation that can be offered for this fluctuation is that in some cases exacerbations were precipitated by prolonged physical exertion. The exacerbations were never related to any infection. Such variation in tolerance to exercise also appears to occur in idiopathic paroxysmal myoglobinuria, as is apparent from case reports on record, though it has never been discussed in detail.

As judged from the high pulse rate during exercise, the circulatory capacity appeared to be a main factor in limiting the patients' tolerance to physical exercise. The normal blood pressures in the heart and blood vessels and the ordinary stroke volume at rest and during exercise at high pulse frequency excluded the possibility of any disorder of the pumping activity of the heart and suggested normal contractility of the heart muscle. Other examinations did not suggest myocardial injury either. At rest the utilization of oxygen in the peripheral tissues was normal, and the general circulation of the blood also appeared normal. During exercise the oxygen content of the mixed venous blood in the pulmonary artery was almost the same as at rest, and the arteriovenous oxygen differences were practically unchanged, suggesting that in the peripheral tissues the utilization of the oxygen of the blood was poor. The cardiac output was large for the amount of oxygen taken up. The rate of the circulation was thus also abnormally high during exercise (hyperkinetic circulation) and even a low work load required the whole circulatory capacity.

As in the acute state, during physical exercise the arterial bicarbonate content and the $p \mathrm{H}$ fell and the lactate and pyruvate concentrations rose. The hyperventilation was probably due to this metabolic acidosis. No pulmonary insufficiency could be demonstrated, and the oxygen saturation of the arterial blood was normal.

On closer analysis of the situation in the peripheral tissues it was found that the oxygen saturation of the blood in the femoral and axillary vein was abnormally high during respectively leg and arm exercise (see Methods). The concentrations of lactate and pyruvate were high for the work performed. During arm exercise, on the other hand, the oxygen saturation decreased at a normal rate in the blood from un-exercised muscles (femoral vein) as well as in blood that had presumably been collected largely from tissues other than muscle tissue (superficial arm vein). This suggests that the regulation of the circulation in resting tissues was normal.

The changes observed strongly suggest the existence of a pathological muscle metabolism. Muscular exercise results in production of excessive amounts of metabolites, which presumably causes 4 abnormal vascular dilatation of the vessels in the muscles (local humoral effect) with consequent hyperkinetic circulation.

The oxygen uptake by the patients increased in a normal way in relation to the work load (Åstrand, 1960) and the mechanical efficiency was normal. Since the work load that the patients were able to perform was low the amount of oxygen consumed by the working muscles was small. This, together with a large blood flow, resulted in a high oxygen saturation of the venous blood from the working muscles. Other hyperkinetic conditions such as vasoregulatory asthenia (Holmgren et al., 1957) can be excluded, since among other things the circulation during rest was normal.

The metabolic disorder may be a manifestation of an oxygen deficit in the muscle cells which may lead to increased anaerobic glycolysis. But the release of oxygen from the blood with a relatively low oxygen content did not appear to be impaired since the oxygen saturation of the blood in the femoral vein decreased normally during arm exercise. Neither does impaired diffusion appear likely in view of the largely normal histological picture of the muscle in the chronic stage. As a third possibility, a decreased capacity of the myoglobin as a depot for oxygen may be considered. The amount of myoglobin in the muscle cells may be reduced or the myoglobin molecule may be abnormal in analogy with the haemoglobin defect in sickle cell anaemia for example. The myoglobin content of the gastrocnemius muscles was examined in three patients, and was found to be about one third of the normal content. The tissue examined had, however, been stored in the frozen state for about three months before the analysis. The $\mathrm{CO}$ affinity of the purified myoglobin from one patient was examined and found not to differ significantly from that of normal myoglobin. ${ }^{1}$

Hed (1955) and Berenbaum, Birch, and Moreland (1955) also found an abnormally low myoglobin concentration in the muscles from patients with idiopathic paroxysmal myoglobinuria. Prankerd (1956) found no difference between electrophoretic patterns of myoglobin from a healthy adult, from a patient with sickle-cell anaemia, and from a patient with paroxysmal myoglobinuria. Unfortunately no details were given about the patient with paroxysmal myoglobinuria except that he had shown no signs of muscle dystrophy. Kossmann, Camp, and Engle (1963) claimed to have demonstrated 'unusual' heme compounds in the urine in a case of idiopathic recurrent rhabdomyolysis with myoglobinuria.

The metabolic disorder can, of course, also be explained by a disturbance of the oxidation system

'The examinations were carried out by Professor K. G. Paul, Department of Medical Chemistry, University of Umeå. 
of the muscle cells. Mitochondria from a muscle biopsy in case A3 were studied by a method described by Azzone, Eeg-Olofsson, Ernster, Luft, and Szabolcsi (1961). The isolated mitochondria showed normal properties regarding respiration $\left(\mathrm{QO}_{2}\right)$, phosphorylation $(\mathrm{P} / \mathrm{O})$, and respiratory intensity (inhibiting effect on respiratory intensity in the absence of phosphate acceptor). No attempts were made to assess the oxygen content of the mitochondria in vivo. ${ }^{1}$

In addition certain glycolytic enzymes, L-DH, G-DH, PYR-K, ENO, P-GLY-K, P-GLY-M, GAP-DH, ALD and HP-I, in muscle biopsy material from cases $\mathrm{C} 1, \mathrm{C} 3$, and D2 studied with a method described by Fellenberg, Eppenberger, Richterich, and Aebi (1962) showed normal activity. ${ }^{2}$

Though no changes so far have been demonstrated in the cellular enzyme system, such a defect may have existed and caused a pathological increase of acid metabolites with the higher rate of metabolism during exercise.

As mentioned in the introduction, Schmid and Mahler (1959) described a case of McArdle's disease with paroxysmal myoglobinuria. The disease is characterized clinically by the fact that a moderate degree of exercise produces marked muscular weakness and cramp-like pain. In McArdle's disease, however, the metabolic disorder of the muscle (McArdle, 1951; Schmid and Mahler, 1959; Pearson, Rimer, and Mommaerts, 1961 ; Thomson, MacLaurin, and Prineas, 1963) is opposite in type to that found in our cases. The normal increase of the lactic acid concentration in the blood during exercise is missing. The oxygen content of the blood from a femoral vein during exercise decreased in the way expected. The anaerobic glycolysis is impaired by the absence of phosphorylase activity. In addition, histological examination of skeletal muscles shows an increased glycogen content.

The functional state of the muscles was also studied electromyographically. After exercise the number of polyphasic action potentials was increased, while the mean duration of the action potentials was decreased. Such changes occurred

\footnotetext{
${ }^{1}$ These examinations were carried out by Dr. L. Ernster, WennerGren's Institute, Stockholm.

${ }^{2}$ These examinations were carried out by Dr. R. Richterich, Medizinisch-Chemisches Institut, Universität, Berne.

L-DH = Lactate-dehydrogenase (E.C. 1.1.1.27).

PYR-K = Pyruvate kinase (E.C. 2.7.1.40).

P-GLY-K = Phosphoglycero kinase (E.C. 2.7.2.3).

GAP-DH = Glyceraldehydephosphate dehydrogenase (E.C. 1.2.1.12)

ALD $\quad=$ Aldolase (E.C. 4.1.2.7).

G-DH = Glucosephosphate dehydrogenase (E.C. 1.1.1.49)

ENO = Enolase (E.C. 4.2.1.11).

P-GLY-M = Phosphoglyceromutase (E.C. 2.7.5.3)

HP-I = Hexosephosphate-isomerase (E.C. 5.3.1.9).
}

also in controls after exercise (see also Buchthal, Pinelli, and Rosenfalck, 1954b), but the increase in the number of polyphasic potentials was significantly larger in the patients, even after much less work thanos that performed by the controls.

A reduction of the duration of the action potentials 0 and an increase in the number of polyphasion potentials has been considered to be characteristic of: diseases in which the number of functioning muscle fibres in the individual motor units is reduced. (Kugelberg, 1947, 1949). It is therefore possible that, during exercise, certain muscle cells are damaged and cease to function. Obviously there may be other explanations. No humoral factor appears to be responsible for such damage since no changes occurred in simultaneous electromyographic tracings of muscles not engaged in the work. The muscle celiss damage must be at least largely reversible, for in $\overrightarrow{0}$ most cases the electromyograms traced after fourhours' rest had regained their original appearance. $\vec{\omega}$ By this time the acidoses following exercise had also disappeared, and the patient had recovered sub jectively.

Even during rest some patients showed electro- myographic signs of muscle cell damage of the saniew type as that observed during exercise. In case $A$, who was studied in an acute state of the disease, lakgeg muscle areas were also electrically inactive. Elect myographic changes at rest have been describedinin idiopathic paroxysmal myoglobinuria (Hed, 1955: Haase and Engel, 1960), but a search of the literatựe failed to reveal any electromyographic investigations after exercise.

The electromyographic changes at rest can be correlated with the morphological findings. The widespread muscle necrosis during the acute states explains why certain muscle areas were electrically inactive. The splitting of action potentials observed during the chronic state can be explained by the slight degeneration of the fibres then observed.

The histological appearance of the muscle fibres after an attack of idiopathic paroxysmal myo globinuria has been studied by various authors including Reiner, Konikoff, Altschule, Dammin:and Merrill (1956). As in our cases, severe and wide spread muscle necrosis was seen. Our investigations show that the regeneration of the muscle fibres is sog pronounced that the muscle makes a practically. complete recovery. It would appear that only? Pearson, Beck, and Blahd (1957) have studied the musculature histologically between the acute attacks and then found no pathological changes withp certainty.

The pathophysiological sequence of events in the్ muscles studied by us may be summarized as follows During work abnormally large amounts of acio 
metabolites are produced, and cannot be eliminated fast enough despite the increased rate of circulation with resultant damage to some of the muscle cells. Clinically this course manifests itself in the form of muscle pain, hardness and tenderness of the muscles, and sometimes pareses, electromyographically reflected in splitting of action potentials. In an early stage muscle cell damage is 'functional' and reversible, but if the damage is more advanced the cells are destroyed. The cell content, including the myoglobin, can then escape into the bloodstream and if the muscle destruction is extensive enough, the myoglobin escapes into the urine. The renal threshold value for myoglobin is about $20 \mathrm{mg} . / 100 \mathrm{ml}$. blood plasma. In other words myoglobinuria is a sign of advanced muscle destruction.

It is, of course, uncertain whether the metabolic disorders demonstrated by us also occur in other cases of paroxysmal myoglobinuria. Only in two cases had the blood lactate been determined. In one of them (Pearson et al., 1957), in which it was measured during an exacerbation, it was found to be normal. In the other case (Kontos et al., 1963) the concentration of lactate in the blood increased during exercise, though probably less than in our patients. The concentration of pyruvate during exercise increased only slightly in comparison with the increase in lactate concentration whereas in our patients the concentration of pyruvate was increased excessively. There are also other striking differences. In the patient described by Kontos et al. the muscle glycogen was increased and the condition did not appear until adult life and no other instances of the disease were known in the family. In addition, the arteriovenous oxygen difference increased substantially during exercise, while in our patients it remained practically unchanged. In their patient the circulation was not hyperkinetic.

The metabolic disorder in our cases is probably due to a defective gene which appears to follow a monohybrid autosomal recessive mode of inheritance. Familial occurrence of idiopathic paroxysmal myoglobinuria appears to be uncommon. Hed (1955) described three brothers with myoglobinuria and Wheby and Miller (1960) three sisters. In Hed's family the mode of inheritance was also recessive. In further cases the authors reported that sibs of the patients had a similar clinical syndrome but they gave no detailed description of the clinical picture of the relatives (Hittmair, 1925; Schaar, LaBree, and Gleason, 1949; Bowden, Fraser, Jackson, and Walker, 1956; Fitz, 1957). It is also probable that some of the familial cases had escaped attention, for the excretion of dark urine was apparently regarded as obligatory for the diagnosis. At this juncture it might not be out of place to refer to an investigation by Schmid and Hammaker (1961) who showed that McArdle's disease most likely is due to a 'single completely recessive, rare, autosomal gene'.

Several of our patients had hypertrophy of the calves. Hypertrophy of the calves has also been described in idiopathic paroxysmal myoglobinuria by Meyer-Betz (1910), Louw and Nielsen (1944), Wissler (1948), Acheson and McAlpine (1953), Hed (1955), and Kontos et al. (1963), so that it is less likely a coincidence of two independent clinical entities. In the family $A$ the hypertrophy of the calves was probably due to a dominant gene. It is possible that the hypertrophy of the calves of the affected members of the families $C, D$, and $E$ was not inherited but due to overactive muscle regeneration.

In some of the cases of idiopathic paroxysmal myoglobinuria with hypertrophied calves progressive muscular dystrophy had been assumed. Louw and Nielsen (1944) expressed the view that 'progressive muscular dystrophy and paralytic myoglobinuria may be different forms of the same disease, the latter representing the acute manifestation of the lesion'. But, as is apparent from the histological examination, for example, it was not a question of muscular dystrophy or pseudohypertrophy in our cases.

\section{SUMMARY}

A myopathy with previously unknown characteristics is described. Fourteen patients belonging to five families were examined.

The disease appears in childhood and runs a chronic course with exacerbations and remissions. It is characterized by low physical performance. Physical exertion soon caused exhaustion, dyspnoea, and palpitation. In continued work the muscles became hard, tender, with supervention of crampand sometimes pareses. But tolerance to work varied. When it was low, an acute state sometimes developed with dyspnoea and tachycardia even at rest, nausea, severe muscular pain, severe and more or less widespread pareses, muscle areflexia, severe acidosis, and sometimes myoglobinuria.

During rest the circulation was normal and the utilization of oxygen in the peripheral tissues was normal. Even slight physical exertion caused tachycardia and a hyperkinetic circulation. During exercise the utilization of the blood oxygen by the working muscles was low, and the concentrations of lactate and pyruvate in the blood increased more than normally for the work load and for the pulse frequency and thereby indicated abnormal glycolysis.

Electromyographic examination at rest sometimes showed signs of myopathy. In one patient examined in an acute state large areas of the muscles were electrically inactive. After exercise the number of 
polyphasic action potentials increased. This may suggest a reduction in the number of functioning muscle fibres in individual motor units.

On histological examination of the muscles during the acute state extensive muscle fibre degeneration was noticed. Even during remissions slight signs of acute degeneration were noticed. Regeneration of the damaged muscle fibre was marked and resulted in complete recovery of the musculature.

The possibility of an accumulation of acid metabolites in the musculature during work is discussed as a cause of muscle cell damage.

The disease appears to be inherited. A monohybrid autosomal recessive mode of inheritance is considered most likely. Hypertrophy of the calves occurred in one of the families as a probably dominant characteristic.

In several respects the clinical picture resembled that seen in some cases of so-called idiopathic paroxysmal myoglobinuria, in which the muscle activity is the precipitating factor. Whether the underlying patho-physiological disorder is the same is not known.

\section{REFERENCES}

Acheson, D., and McAlpine, D. (1953). Lancet, 2, 372

Åstrand, I. (1960). Acta physiol. scand., suppl. 169.

Azzone, G. F., Eeg-Olofsson, O., Ernster, L., Luft, R., and Szabolcsi, G. (1961). Exp. Cell. Res., 22, 415.

Barker, S. B., and Summerson, W. H. (1941). J. biol. Chem., 138, 535. Berenbaum, M. C., Birch, C. A., and Moreland, J. D. (1955). Lancet, 1, 892.

Berlin, R. (1948). Acta med. scand., 129, 560.

Bowden, D. H., Fraser, D., Jackson, S. H., and Walker, N. F. (1956). Médicine, 35, 335 .

Buchthal, F., Guld, C., and Rosenfalck, P. (1954a). Acta physiol. scand., 32, 200.

_, Pinelli, P., and Rosenfalck, P. (1954b). Ibid., 32, 219.

Bywaters, E. G. L. (1944). J. Amer. med. Ass., 124, 1103.

-, and Stead, J. K. (1945). Clin. Sci., 5, 195.

Carlson, L. A., and Pernow, B. (1959). Acta med. scand., 164, 39.

Daugherty, G. W., Kaye, R. L., and Mathieson, D. R. (1959). Proc. Mayo Clin., 34, 395.

Farmer, T. A., Hammack, W. J., and Frommeyer, W. B. (1961). New Engl. J. Med., 264, 60.
Fellenberg, R. von, Eppenberger, H., Richterich, R., and Aebi, H (1962). Biochem. Z., 336, 334.

Fischer, H., and Rossier, P. H. (1947), Helv. med. Acta, 14, 212.

Fitz, T. E. (1957). W. Va. med. J., 53, 264.

Friedemann, T. E., and Haugen, G. E. (1943). J. biol. Chem., 147, 41sc

Gillett, R. L. (1959). New Engl. J. Med., 260, 1156.

Günther, H. (1924). Virchows Arch. path. Anat., 251, 141.

Haase, G. R., and Engel, A. G. (1960). Arch. Neurol., 2, 410.

Hed, R. (1955). Acta med. scand., suppl. 303.

Hittmair, A. (1925). Wien. klin. Wschr., 38, 431.

Holmgren, A., Jonsson, B., Levander, M., Linderholm, H., Sjöstrand T., and Ström, G. (1957). Acta. med. scand., 158, 413. and Sjöstrand, T. (1960). Acta physiol. scand., 49, 343. and Mattsson, K. H. (1954). Scand. J. clin. Lab. Invest., 6, 137: , and Pernow, B. (1959). Ibid., 11, 143.

- and Ström, G. (1959). Acta med. scand., 163, 185.

Huckabee, W. E. (1956). J. appl. Physiol., 9, 163.

Javid, J., Horowitz, H. I., Sanders, A. R., and Spaet, T. H. (1959) Arch. intern. Med., 104, 628.

Jørgensen, K., and Astrup, P. (1957). Scand. J. clin. Lab. Invest., $9 \overline{\bar{T}}$ 122.

Kontos, H. A., Harley, E. L., Wasserman, A. J., Kelly, J. J., and Magee, J. H. (1963). Amer. J. Med., 35, 283.

Korein, J., Coddon, D. R., and Mowrey, F. H. (1959). Neurology (Minneap.), 9, 767.

Kossmann, R. J., Camp, W. A., and Engle, R. L. (1963). Amer. Med., 34, 554.

Kugelberg, E. (1947). J. Neurol. Neurosurg. Psychiat., 10, 122. (1949). Ibid, 12, 129.

Louw, A., and Nielsen, H. E. (1944). Acta med. scand., 117, 424. McArdle, B. (1951). Clin. Sci., 10, 13.

Meyer-Betz, F. (1910). Dtsch. Arch. klin. Med., 101, 85.

Paul, F. (1924). Wien. Arch. inn. Med., 7, 531.

Pearson, C. M., Beck, W. S., and Blahd, W. H. (1957). Arch. internig Med., 99, 376.

_, Rimer, D. G., and Mommaerts, W. F. H. M. (1961). Ame Med., 30, 502.

Phillippi, P. J., Jones, F. R., and Kenoyer, W. L. (1960). J. Amer. מִ̣d? Ass., 172, 907.

Prankerd, T. A. J. (1956). Brit. J. Haemat., 2, 80.

Reiner, L., Konikoff, W., Altschule, M. D., Dammin, G. J., 赵员 Merrill, J. P. (1956). Arch. intern. Med., 97, 537.

Schaar, F. E., LaBree, J. W., and Gleason, D. F. (1949). J. Lab. Sin? Med., 34, 1744.

Schmid, R., and Hammaker, L. (1961). New Engl. J. Med., 264, $2 \frac{23}{2}$

- and Mahler, R. (1959). J. clin. Invest., 38, 0244.

Seldinger, S. I. (1953). Acta radiol., 39, 368.

Sjöstrand, T. (1947). Acta med. scand., suppl. 196. 687.

Van Slyke, D. D., and Neill, J. M. (1924). J. biol. Chem., 61, 523.

Ström, G. (1949). Acta physiol. scand., 17, 440.

Thomson, W. H. S., MacLaurin, J. C., and Prineas, J. W. (1963) J. Neurol. Neurosurg. Psychiat., 26, 60.

Wahlund, H. (1948). Acta med. scand., suppl. 215.

Wheby, M. S., and Miller, H. S. (1960). Amer. J. Med., 29, 599.

Wissler, H. (1948). Helv. paediat. Acta, 3, 334. 